\begin{tabular}{|l|l|}
\hline 2. To: (Receiving Organization) & 3. From: (Originating Organization) \\
FFTF Engineering & NUMATEC Hanford Corporation \\
\hline 5. Proj./Prog./Dept./Div.: & 6. Design Authority/ Design Agent/Cog. \\
FFTF & F. J. Heard \\
\hline
\end{tabular}

8. Originator Remarks:

Transmittal of HNF-1732, Preliminary Scoping Safety Analyses of The Limjting Design Basis Protected Accidents For The Fast Flux Test Facility Tritium Production Core

11. Receiver Remarks: 11A. Design Baseline Document? [] Yes $[\mathrm{X}]$ No

\begin{tabular}{|} 
4. Related EDT No.: \\
N/A \\
\hline $\begin{array}{r}\text { 7. Purchase Order No.: } \\
\text { N/A }\end{array}$ \\
\hline
\end{tabular}

9. Equip./Component No.:

$N / A$

10. System/Bldg./Facility:

$N / A$

12. Najor Assm. Dwg. No.:

$N / A$

13. Permit/Permit Application No.: $N / A$

14. Required Response Date: November 19, 1997

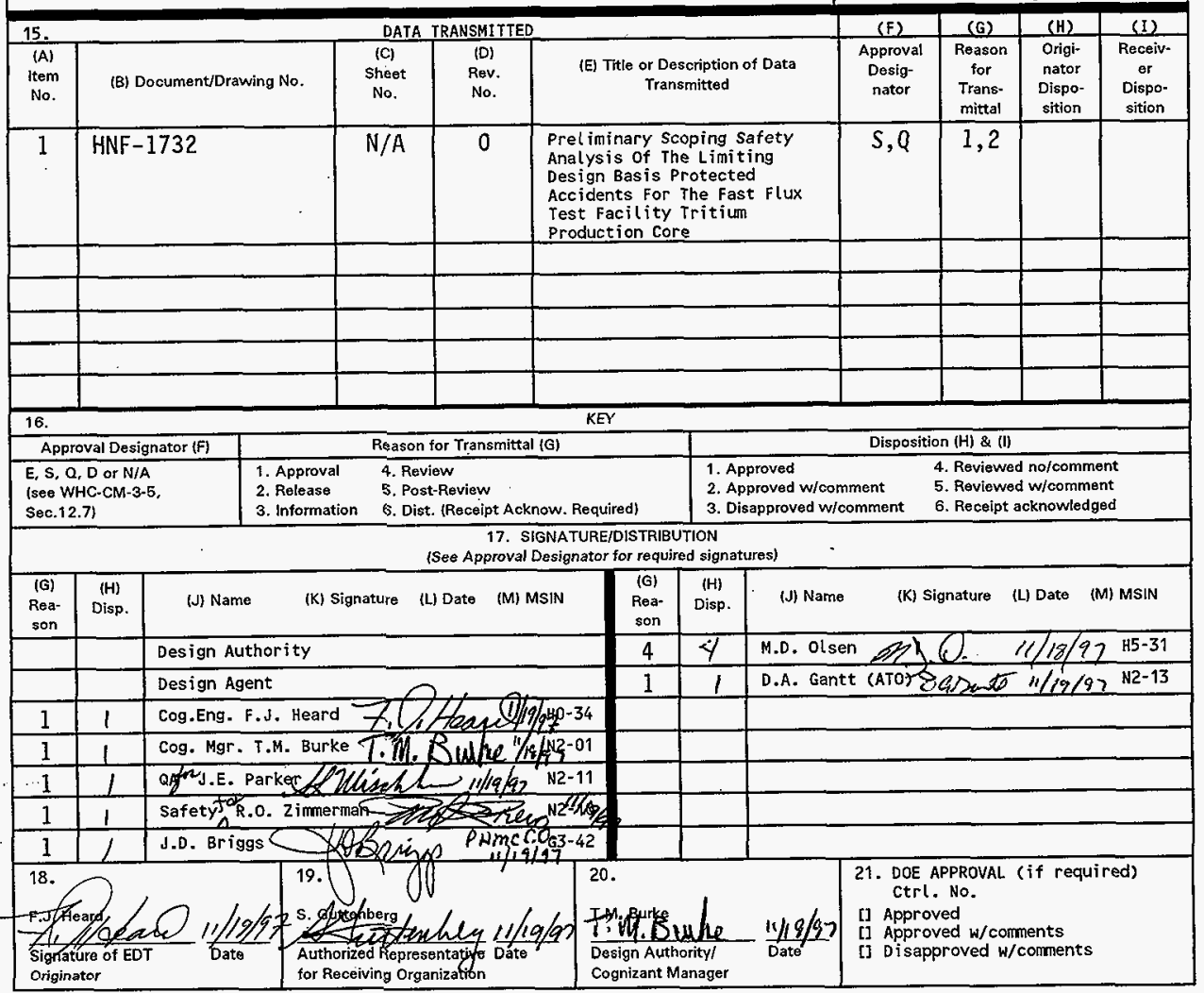




\title{
Preliminary Scoping Safety Analyses Of The Limiting Design Basis Protected Accidents For The Fast Flux Test Facility Tritium Production Core
}

\author{
F. J. Heard
}

NUMATEC Hanford Corporation, Richland, WA 99352

U.S. Department of Energy Contract DE-AC06-96RL13200

$\begin{array}{lll}\text { EDT/ECN: } & 619617 & \text { UC: } 542 \\ \text { Org Code: } & \text { UC530000 } & \text { Charge Code: } \\ \text { B\&R Code: } & \text { EX7002000 } & \text { Total Pages: } 5 \& 61 \omega_{1}-2 q^{-97}\end{array}$

Key Words: Safety Analyses, Limiting Design, Protected Accidents, FFTF, Tritium, Tritium Production Core

Abstract: The SAS4A/SASSYS-1 computer code is used to perform a series of analyses for the limiting protected design basis transient events given a representative tritium and medical isotope production core design proposed for the Fast Flux Test Facility. The FFTF tritium and isotope production mission will require a different core loading which features higher enrichment fuel, tritium targets, and medical isotope production assemblies. Changes in several key core parameters, such as the Doppler coefficient and delayed neutron fraction will affect the transient response of the reactor. Both reactivity insertion and reduction of heat removal events were analyzed. The analysis methods and modeling assumptions are described. Results of the analyses and comparison against fuel pin performance criteria are presented to provide quantification that the plant protection system is adequate to maintain the necessary safety margins and assure cladding integrity.

TRADEMARK DISCLAIMER. Reference herein to any specific commercial product, process, or service by trade name, trademark, manufacturer, or otherwise, does not necessarily constitute or imply its endorsement, recommendation, or favoring by the United States Government or any agency thereof or its contractors or subcontractors.

Printed in the United States of America. To obtain copies of this document, contact: Document Control Services, P.0. Box 950, Mailstop H6-08, Richland WA 99352, Phone (509) 372-2420;

Fax (509) 376-4989.
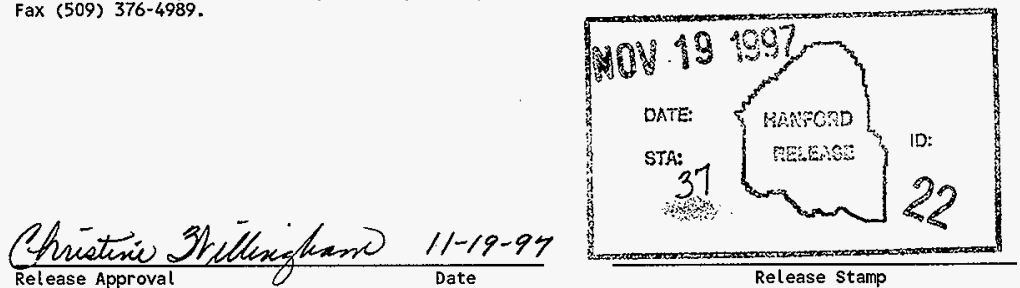
HNF-1732

PRELIMINARY SCOPING SAFETY ANALYSES OF THE LIMITING DESIGN BASIS PROTECTED ACCIDENTS FOR THE FAST FLUX TEST FACILITY

TRITIUM PRODUCTION CORE

November 1997

By

F. J. Heard

NUMATEC HANFORD CORPORATION

P. O. Box 1500

Richland, Wa.

Prepared for the U.S. Department of Energy

Richland Operations Office

Richland, Washington 
HNF-1732

\section{ACKNOWLEDGMENT}

The author gratefully acknowledges the help of the Reactor Analysis Division staff at Argonne National Laboratory. Their inexhaustible patience and support was very much appreciated and was central to the successful completion of this document.

Also, thanks to J. C. VanKeuren of Fluor Daniel Northwest Services, for performing the cladding strain calculations documented in this report. 


\title{
HNF-1732
}

\section{PRELIMINARY SCOPING SAFETY ANALYSES OF THE LIMITING DESIGN BASIS PROTECTED ACCIDENTS FOR THE FAST FLUX TEST FACILITY TRITIUM PRODUCTION CORE}

\begin{abstract}
The SAS4A/SASSYS-1 computer code is used to perform a series of analyses for the limiting protected design basis transient events given a representative tritium and medical isotope production core design proposed for the Fast Flux Test Facility. The FFTF tritium and isotope production mission will require a different core loading which features higher enrichment fuel, tritium targets, and medical isotope production assemblies. Changes in several key core parameters, such as the Doppler Coefficient and the delayed neutron fraction, will affect the transient response of the reactor. Both reactivity insertion and reduction of heat removal events were analyzed. The analysis methods and modeling assumptions are described. Results of the analyses and comparison against fuel pin performance criteria are presented to provide quantification that the plant protection system is adequate to maintain the necessary safety margins and assure cladding integrity.
\end{abstract}


HNF-1732

\section{TABLE OF CONTENTS}

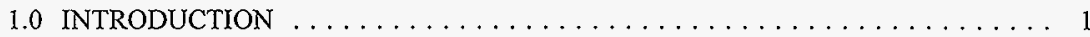

1.1 PURPOSE AND OBJECTIVE $\ldots \ldots \ldots \ldots \ldots \ldots \ldots \ldots \ldots \ldots \ldots$

1.2 BACKGROUND AND MISSION DESCRIPTION $\ldots \ldots \ldots \ldots \ldots \ldots \ldots$

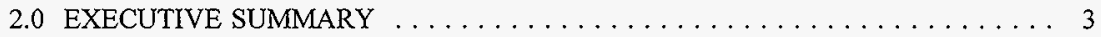

3.0 SUMMARY OF EXISTING FSAR ANALYSES $\ldots \ldots \ldots \ldots \ldots \ldots \ldots \ldots$

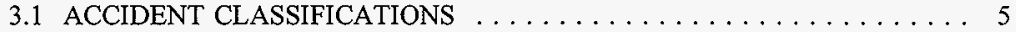

3.2 CLADDING TEMPERATURE AND STRAIN LIMITS $\ldots \ldots \ldots \ldots \ldots 5$

3.3 FSAR ANALYSIS METHODS $\ldots \ldots \ldots \ldots \ldots \ldots \ldots \ldots \ldots \ldots$

4.0 CHARACTERISTICS OF THE TRITIUM PRODUCTION CORE . . . . . . 10

4.1 STRUCTURE CHARACTERISTICS - CLADDING AND DUCT

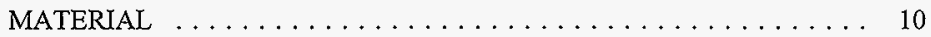

4.2 THERMAL-HYDRAULIC CHARACTERISTICS . . . . . . . . 11

4.3 NEUTRONIC CHARACTERISTICS $\ldots \ldots \ldots \ldots \ldots \ldots \ldots \ldots \ldots .11$

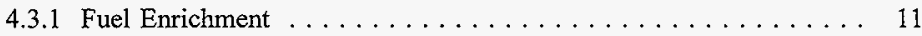

4.3.2 Reactivity Feedbacks $\ldots \ldots \ldots \ldots \ldots \ldots \ldots \ldots \ldots \ldots$

4.3.3 Other Neutronic Parameters $\ldots \ldots \ldots \ldots \ldots \ldots \ldots \ldots . \ldots \ldots$

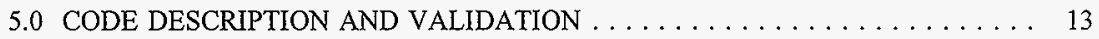

5.1 SAS4A/SASSYS-1 VERSION 3.0 HANFORD REVISION $1.0 \ldots \ldots \ldots \ldots 13$

5.2 SAS4AJSASSYS-1 Code Installation Verification and Validation . . . . . 14

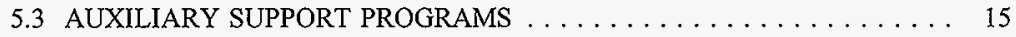

5.3.1 COMBINE Computer Code $\ldots \ldots \ldots \ldots \ldots \ldots \ldots \ldots \ldots$

5.3.2 DECAY Computer Code ................... 15

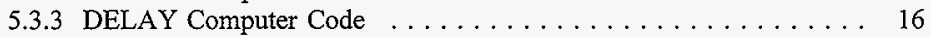

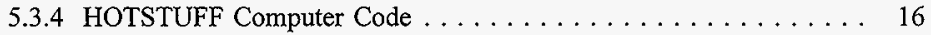

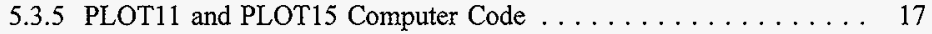

6.0 MODEL DEVELOPMENT AND ASSUMPTIONS $\ldots \ldots \ldots \ldots \ldots \ldots \ldots \ldots$

6.1 MODEL DEVELOPMENT $\ldots \ldots \ldots \ldots \ldots \ldots \ldots \ldots \ldots \ldots \ldots \ldots \ldots \ldots$

6.1.1 Channel Selection $\ldots \ldots \ldots \ldots \ldots \ldots \ldots \ldots \ldots \ldots \ldots$

6.1.2 Tritium Target $P_{\text {in }}$ Thermal Model $\ldots \ldots \ldots \ldots \ldots \ldots \ldots \ldots$

6.1 .3 Balance-of-Plant Model .................. 20

6.1.4 Reactor Control, Plant Control, and Plant Protection System

Models ........................ 21

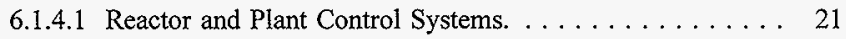

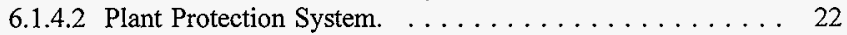

6.2 HOT CHANNEL FACTORS $\ldots \ldots \ldots \ldots \ldots \ldots \ldots \ldots \ldots \ldots \ldots \ldots$ 


\section{HNF-1732}

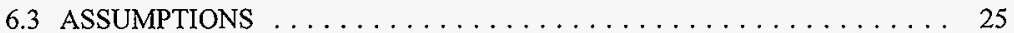

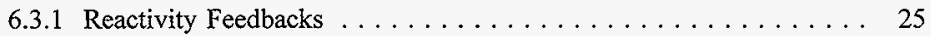

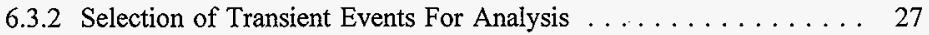

6.3.2.1 Reactivity Insertion (Transient Overpower) Events. . . . . 27

6.3.2.2 Design Basis Reduction of Heat Removal Event . . . . . 27

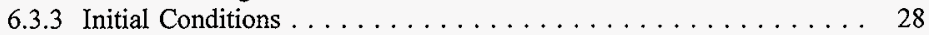

7.0 RESULTS OF THE PROTECTED DESIGN BASIS EVENTS . . . . . . . . . 35

7.1 TRANSIENT OVERPOWER EVENTS $\ldots \ldots \ldots \ldots \ldots \ldots \ldots \ldots \ldots$

7.1.1 Fast Reactivity Insertion $(3 \$ / \mathrm{s}) \ldots \ldots \ldots \ldots \ldots \ldots \ldots \ldots$

7.1.2 Slow Reactivity Insertion $(0.032 \%$ Power $/ \mathrm{s}) \ldots \ldots \ldots \ldots . \ldots 36$

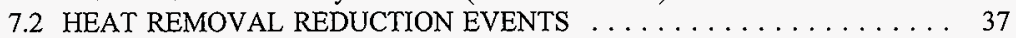

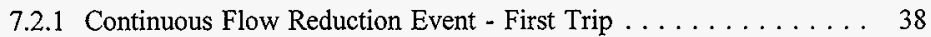

7.2.2 Continuous Flow Reduction Event - Second Trip . . . . . . . . . . 39

8.0 SUMMARY AND CONCLUSIONS $\ldots \ldots \ldots \ldots \ldots \ldots \ldots \ldots \ldots \ldots$

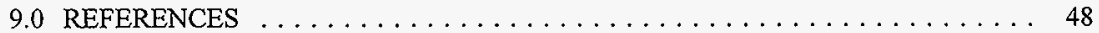

APPENDIX A. Transient Performance of FFTF Tritium Targets 
HNF-1732

\section{LIST OF TABLES}

3-1. Existing FFTF FSAR Limits for Reactor Accident Analyses.

6-1. Direct, Statistical, and Combined FFTF Hot Channel Factors

6-2. Trip Inputs to the Reactor Shutdown System as Modeled for the Tritium Production Core.

7-1. Results of the 3\$/s Transient Overpower Analysis.

7-2. Results of the $0.032 \%$ Power/s Transient Overpower Analysis.

7-3. Hot Channel Temperatures Obtained for the Continuous Flow Reduction Events.

8-1. Comparison of FSAR and Calculated Results for the Tritium Production Core. 
HNF-1732

\section{LIST OF FIGURES}

3-1. Maximum Allowable Cladding Midwall Temperatures at Hot Channel Conditions Versus Peak Fuel Burnup.

6-1. Representative Planar View of FFTF Target Pin

6-2. One-Loop Balance Of Plant Model for FFTF

6-3. Two-Loop Balance Of Plant Model for FFTF

6-4. Identification of FFTF Hot Channel Factors As Determined from Pin, Assembly, and Core Regions

7-1. Normalized Reactor Power and Channel Flow Versus Time for the 3\$/s Transient Overpower Event.

7-2. Power-To-Flow Ratio Versus Power During a Continuous Flow Reduction Event for Secondary RSS Flux and Flow Related Trip Functions.

7-3. Power-To-Flow Ratio Versus Power During a Continuous Flow Reduction Event for Primary RSS Flux and Pressure Related Trip Functions.

7-4. Hot Channel Clad Midwall Temperature Versus Time During the Continuous Flow Reduction Events as Terminated by the Primary and Secondary RSS Trip Functions. 
HNF-1732

\section{LIST OF TERMS}

BEC - Beginning of Equilibrium Cycle

BOL - Beginning of Life

CFR - Continuous Flow Reduction

CIS - Containment Isolation System

CSI - Control System Input

DFA - Driver Fuel Assembly

DHX - Dump Heat Exchanger

DOE - Department of Energy

EEC - End of Equilibrium Cycle

EFPD - Equivalent Full Power Day

EOL - End of Life

FFTF - Fast Flux Test Facility

FSAR - Final Safety Analysis Report

HTS - Heat Transport System

IHX - Intermediate Heat Exchanger

LMR - Liquid Metal Reactor

LOF - Loss-Of-Flow

MIA - Medical Isotope Assembly

MTM - Metric Ton heavy Metal (Uranium + Plutonium)

MWd - MegaWatt-days

PPS - Plant Protection System

RSS - Reactor Shutdown System

SG - Steam Generator

TA - Tritium Assembly

TOP - Transient Overpower

ULOF - Unterminated Loss-Of-Flow

UTOP - Unterminated Transient Overpower 


\section{HNF-1732}

\subsection{INTRODUCTION}

\subsection{PURPOSE AND OBJECTIVE}

The purpose of this report is to document the results of the analyses that were performed to evaluate the adequacy of the existing Reactor Shutdown System (RSS) to maintain cladding integrity during a series of limiting design basis events for the proposed tritium and medical isotope production core at the Fast Flux Test Facility (FFTF) or to identify system modifications that might be required.

The objective of these analyses is to calculate the maximum cladding midwall temperatures and cladding strains that could result given the most limiting design basis events.

Section 2.0 presents an executive summary of the most pertinent results and conclusions. Section 3.0 contains a brief review of the applicable FSAR safety analyses and the appropriate limits for cladding strain and midwall temperature. Section 4.0 discusses the changes in core parameters and characteristics for the tritium production core. Section 5.0 discusses the computer programs that were used for the analyses. Section 6.0 presents a detailed description of the multi-channel core model that was constructed to perform the subject analyses and the assumptions that were used. The results of the analyses are presented in Section 7.0. A summary of the results and discussion of the conclusions is presented in Section 8.0. Section 9.0 documents the references for this report.

\subsection{BACKGROUND AND MISSION DESCRIPTION}

The FFTF is a U. S. Government-owned $400 \mathrm{MWt}$ sodium-cooled, fast-neutron flux reactor originally designed for the irradiation testing of fuels, materials, and components for use in large liquid metal reactors (LMR). The high neutron flux within FFTF's core provides a extraordinary rich environment to produce isotopes. The FFTF was operated from April 1982 until March 1992 and is located on the Department of Energy's Hanford site near Richland, Washington. In 1992 the plant was placed into a standby condition pending identification of further missions. However, lacking a clear mission, activities to achieve a permanent shutdown were commenced in 1994.

In January of 1997, the United States Department of Energy (DOE) directed that the Fast Flux Test Facility (FFTF) again be placed into a standby condition to permit DOE to make a decision (by 1998) on whether the facility should play a role in the DOE's tritium and medical isotope production strategy. Furthermore, DOE directed that additional safety and 
HNF-1732

environmental studies be conducted during this standby period that could support future nuclear safety or National Environmental Protection Act documentation.

The Fast Flux Test Facility Startup Project Office authorized an initial series of preliminary core management and safety analyses necessary to support both tritium and medical isotope production. To this end, a number of studies have been performed. This report documents the analysis of selected limiting design basis reactor accidents. These accident analyses were performed to confirm that the existing Reactor Shutdown System (RSS) is adequate to maintain fuel cladding temperatures/strains within the existing Final Safety Analysis Report (FSAR) limits (or to identify RSS modifications that might be required). 


\section{HNF-1732}

\subsection{EXECUTIVE SUMMARY}

A wide range of postulated reactor accidents was previously analyzed in the existing FFTF FSAR. These included design basis accidents in the Anticipated, Unlikely and Extremely Unlikely event categories plus very low probability beyond design basis (Hypothetical) events. (Note that a re-evaluation of the very low probability beyond design basis events, described in Appendix A of the FSAR, has been performed by the Argonne National Laboratory and is the subject of a separate report.)

Selected limiting protected design basis accidents have been reanalyzed given a representative tritium and medical isotope production core design proposed for FFTF. The FFTF tritium and isotope production mission will require a different core loading, which features higher enrichment fuel and non-fueled tritium targets and medical isotope production assemblies. The results of the analyses show that the protected transient results are quite similar to the existing FSAR results and that the current RSS is indeed adequate to assure cladding integrity for both the driver fuel and tritium target assemblies.

Two transient overpower (TOP) events and one heat removal reduction event, the continuous flow reduction (CFR), were selected for reanalysis. In the existing FSAR, only two design basis transient overpower events led to any significant calculated fuel cladding strain and only the CFR event challenged the peak hot channel cladding midwall temperature limits.

The calculated maximum incremental cladding strains resulting from both very rapid and slow transient overpower design basis events, $0.062 \%$ and $0.31 \%$, respectively, are within the established FSAR limits of $0.4 \%$ incremental strain $(0.7 \%$ total).

The calculated peak hot channel cladding midwall temperatures for the design basis heat removal reduction events are also within the established burnup dependent FSAR limits of $1490^{\circ} \mathrm{F}$ and $1584^{\circ} \mathrm{F}$ for anticipated and unlikely events, respectively, given a driver fuel assembly peak burnup of $80,000 \mathrm{MWd} / \mathrm{MTM}$. (Increased cladding midwall temperatures are allowed for reduced peak burnups.) The hot channel cladding midwall temperature for the continuous flow reduction given the first (anticipated) and backup (unlikely) trips are $1500^{\circ} \mathrm{F}$ and $1556^{\circ} \mathrm{F}$, respectively. The CFR for the first trip slightly exceeds the most conservative limit of $1490^{\circ} \mathrm{F}$. However, given the calculated assembly peak burnup of 67,000 $\mathrm{MWd} / \mathrm{MTM}$, the corresponding FSAR limit is $1518^{\circ} \mathrm{F}$.

The tritium target maximum hot channel cladding inner diameter temperature was determined to be less than $1500^{\circ} \mathrm{F}$ for all of the design basis transients that were analyzed.

The results of these analyses clearly demonstrate that the existing RSS is adequate to maintain the necessary safety margins and to assure that the calculated cladding temperatures 


\section{HNF-1732}

and strains are within the FSAR limits. Cladding integrity is assured for the proposed tritium and medical isotope production core. (These limits are expected to be somewhat conservative for the new core design due to reduced fuel burnup and the expected use of D9 as an improved cladding and ducting material.) 


\section{HNF-1732}

\subsection{SUMMARY OF EXISTING FSAR ANALYSES}

The existing FFTF FSAR documents the analysis of a wide range of reactor accidents ranging from relatively benign events, which can be expected to occur several times in the lifetime of the plant, to very severe accidents which are of such low probability that they were considered beyond the design basis for the plant.

\subsection{ACCIDENT CLASSIFICATIONS}

The reactor accidents can be grouped into three major categories:

- $\quad$ Reactivity insertion (or transient overpower) events (e.g., uncontrolled withdrawal or meltdown of a control rod)

- $\quad$ Reduction in reactor heat removal (e.g., reduction or loss of primary or secondary sodium flow or DHX air flow)

- $\quad$ Local fuel failure events (e.g., local flow blockage).

Within each of these major categories, several specific events were identified and classified as either Anticipated, Unlikely, Extremely Unlikely or Hypothetical (beyond the design basis for the plant but analyzed to evaluate and demonstrate margins in the plant design). A re-evaluation of the very low probability beyond design basis events, described in Appendix A of the FSAR, has been performed by the Argonne National Laboratory and is the subject of a separate report.

\subsection{CLADDING TEMPERATURE AND STRAIN LIMITS}

The purpose of the subject safety analyses was to evaluate the reactor response of the new core design to the identified events and to demonstrate adequate margins exist to maintain both fuel and tritium assembly cladding integrity. The fuel and tritium pin cladding provides the first barrier to radiation release. The Reactor Shutdown System (RSS) was designed to assure that fuel cladding integrity was maintained for all Anticipated and Unlikely events. Driver fuel pin cladding integrity limits have been derived in terms of cladding strain for transient overpower events and in terms of cladding midwall temperature for reduction of heat removal events. The specific fuel pin FSAR limits are presented in Table 3-1. One additional constraint was applied for the tritium assemblies during the subject analyses. The maximum hot channel clad inner diameter temperature for the tritium pins must be less than $1500^{\circ} \mathrm{F}$. 


\section{HNF-1732}

In the existing FSAR, only two design basis transient overpower type events led to any significant calculated fuel cladding strain:

- $\quad$ The "PPS Design Basis Event" (reactivity insertion of $\$ 3$ per second, $4 \$$ total insertion, which bounds limiting scenarios such as meltdown of a fuel assembly or control rod) resulted in a calculated cladding strain of $0.13 \%$. (This event is actually classified as an Extremely Unlikely event.)

- A very slow (non-mechanistic) reactivity insertion transient, equivalent to 0.032 $\%$ Power/s, with failure of the first PPS trip function resulted in a calculated cladding strain of $0.28 \%$. (This event is also classified as an Extremely Unlikely event.)

In addition, only one design basis heat removal reduction event challenged the FSAR cladding midwall temperature limits. The CFR event is assumed to be initiated through a failure of the primary pump flow controller. The primary flow is slowly reduced. Reactor power is also slowly reduced due to temperature dependent negative reactivity feedbacks, but not as fast as the flow. Consequently the core transient power-to-flow ratio exceeds 1.0 and increased cladding temperatures will occur. The continuous flow reduction (CFR) was analyzed for two different scenarios:

- $\quad$ Termination of the CFR event assuming the first trip function encountered actuates a reactor scram. This event is classified as Anticipated.

- $\quad$ Termination of the CFR event assuming the first trip function encountered failures to activate a reactor scram. Scram is initiated by the second backup trip function. This event is classified as Unlikely.

\subsection{FSAR ANALYSIS METHODS}

The existing FSAR design basis accident calculations were performed with computer codes developed specifically for the FFTF. These were the MELT code for the transient overpower events and the IANUS code for the reactor undercooling events. (See Chapter 15 and Appendix $\mathrm{F}$ of the existing FSAR for additional details concerning the analysis methodology, results, and code references.)

The MELT and IANUS computer codes are relatively simple compared to codes that were developed later to support the United States Liquid Metal Reactor (LMR) program. For example, the MELT code models only the neutronics and thermal-hydraulics of the reactor core (represented by multiple channels); and requires inlet and outlet sodium coolant temperatures and pressure boundary conditions as input. On the other hand, IANUS includes 


\section{HNF-1732}

a detailed model of the reactor Heat Transport System (HTS), but a relatively simple point kinetics neutronics and single channel thermal hydraulics core model. In both models, limiting nuclear peaking factors and "Hot Channel Factors" were applied to account for the effects of local power variations, sodium flow redistribution, the effects of fuel manufacturing uncertainties, and the effects of uncertainties in the thermo-physical properties of the materials. The Hot Channel Factors are discussed in Section 6.2 and presented in Table 6-1. 
HNF-1732

TABLE 3-1. Existing FFTF FSAR Limits for Reactor Accident Analyses

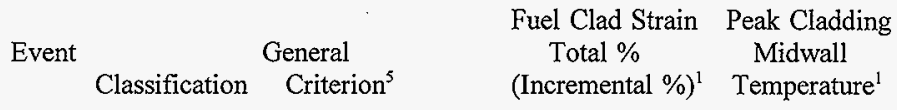

\begin{tabular}{llll}
\hline \hline Anticipated & $\begin{array}{l}\text { Included in } \\
\text { Fuel Lifetime }\end{array}$ & $0.3^{(2)}(0.1)$ & $1490^{\circ} \mathrm{F}$ \\
Unlikely & $\begin{array}{l}\text { Maintain Clad } \\
\text { Integrity }\end{array}$ & $0.7^{(3)}(0.4)$ & $1584^{\circ} \mathrm{F}$ \\
Extremely & \multicolumn{2}{c}{$\begin{array}{l}\text { Assure Coolable } \\
\text { Gnlikely }\end{array}$} & $\begin{array}{c}\text { Prevent Clad } \\
\text { Melting }\end{array} \quad \begin{array}{l}\text { Prevent Sodium } \\
\text { Boiling }\left(1670^{\circ} \mathrm{F}\right)^{4}\end{array}$ \\
Hypothetical & $\begin{array}{l}\text { Analyzed to evaluate/demonstrate margins in design. } \\
\text { FSAR demonstrates primary and containment boundaries remain intact } \\
\text { and offsite radiological consequences are relatively minor in spite of } \\
\text { core disruption. }\end{array}$
\end{tabular}

NOTES:

(1) For reactor overpower type events, clad strain can result from both clad heating and fuel/clad interaction, thus clad strain limits are applied. For reduction of heat removal or loss of cooling type events, clad strain results only from clad heating and thus the strain limits are conservatively converted to cladding midwall temperature limits.

(2) Includes $0.2 \%$ clad strain for normal operation and $0.1 \%$ clad strain for Anticipated events.

(3) Includes $0.2 \%$ clad strain for normal operation, $0.1 \%$ clad strain for Anticipated events, and $0.4 \%$ strain for unlikely events.

(4) Conservatively applied at the cladding outer diameter $\left(\leq 1670^{\circ} \mathrm{F}\right)$.

(5) The maximum hot channel cladding inner diameter temperature for any tritium target pin must be less than $1500^{\circ} \mathrm{F}$. 
HNF-1732

Figure 3-1. FSAR Maximum Allowable Cladding Midwal1 Temperature at Hot Channel Conditions Versus Peak Fuel Burnup

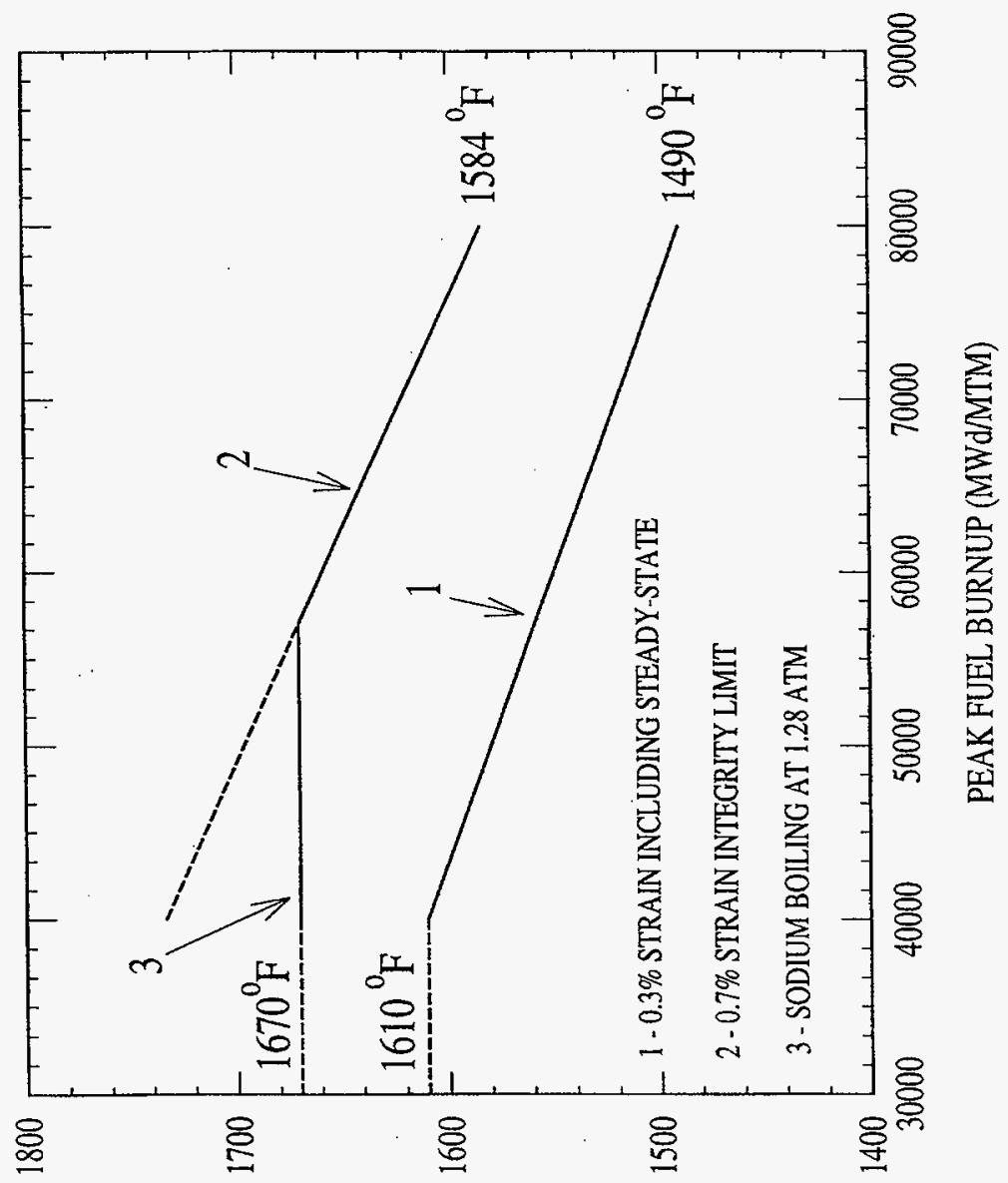

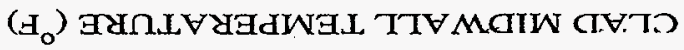




\section{HNF-1732}

\subsection{CHARACTERISTICS OF THE TRITIUM PRODUCTION CORE}

The proposed tritium and medical isotope production mission at FFTF utilizes 90 of the outer row locations, previously occupied by stainless steel reflectors, as well as 16 in-core locations for tritium assemblies and three locations for medical isotope production assemblies.

The planned operating conditions for the proposed tritium and medical isotope production mission are: core power of $400 \mathrm{MW}$, total reactor flow rate of $1.748 \mathrm{E}+07$ pounds per hour and reactor inlet temperature of $680^{\circ} \mathrm{F}$. The proposed mission will require higher enriched fuel, which will affect the transient response of the core. This difference and others from the previous operational cores are discussed in the following sections.

\subsection{STRUCTURE CHARACTERISTICS - CLADDING AND DUCT MATERIAL}

The reference FFTF Series I and II fuel designs used $20 \%$ cold worked 316 stainless steel for both the fuel pin cladding and fuel assembly ducts. It is currently planned to use D9 alloy for these components in the new core design. The upper handling socket and lower inlet nozzle/shield orifice will be fabricated from 316 stainless steel and mechanically attached to the $\mathrm{D} 9$ duct. The remaining core and vessel components will, as before, remain fabricated from 316 stainless steel. No additional changes to the core or vessel internals are anticipated.

The primary reason that $\mathrm{D} 9$ will be used in the new core design is the superior performance of D9 in a fast neutron environment. D9 has been shown, through a series of incore tests ranging from small material coupons through the long term irradiation of full scale fuel assemblies, to be considerably less prone to irradiation induced damage than 316 stainless steel. The cladding strain/temperatures as documented in the existing FSAR were developed for 316 stainless steel and are expected to be conservative for the new core, especially when combined with reduced fuel burnup anticipated for the new core.

One possible effect is some change to the structural reactivity feedbacks. This effect is due to reduced radial swelling and axial growth of the D9 clad fuel pins and ducts during irradiation. The new core is expected to retain more of the interassembly gaps and separation distance from the core restraint system when compared with previous 316 stainless steel cores. Some core movement will occur due to thermal expansion during transient overpower or lossof-flow events. However, due to the long time constants associated with some of the more massive core components, the relatively short term limiting protected design basis events are generally unaffected by structural feedbacks. 


\section{HNF-1732}

\subsection{THERMAL-HYDRAULIC CHARACTERISTICS}

The thermal-hydraulic conditions for the new tritium production core are similar to, but typically less severe than, those used for the FSAR calculations. For example, the new core design includes 81 fuel assemblies compared to 76 for the FSAR core. This, combined with lower calculated radial peaking factors, results in a peak linear heat generation rate at full power of approximately $12.5 \mathrm{~kW} / \mathrm{ft}$ at Beginning of Life (BOL) for the new core compared to $14.3 \mathrm{~kW} / \mathrm{ft}$ for the FSAR calculations.

It should be noted that the calculated operating conditions for the new core are representative of nominal equilibrium reference core conditions and may not reflect the most limiting conditions that could be obtained. For FSAR type calculations, a more limiting core loading/power distribution may be selected to allow flexibility in the core design and additional conservatism in the safety analyses.

\subsection{NEUTRONIC CHARACTERISTICS}

The FFTF tritium and isotope production mission will require a different core loading which features higher enrichment fuel, tritium targets, and medical isotope production assemblies. These differences will affect the transient response of the reactor via changes in core parameters such as the Doppler coefficient and the delayed neutron fractions. The following sections discuss the neutronic characteristics of the new core design.

\subsubsection{Fuel Enrichment}

The large number of neutron absorbing tritium target assemblies requires a higher enrichment. The new reference core uses a plutonium enrichment of up to $42 \%$ compared to approximately $22-29 \%$ for the FSAR core. This has two major impacts in the safety analyses. First, it has a significant effect on some of the reactivity feedbacks (these are discussed below). Second, the core isotopic inventory changes (due to the higher plutonium enrichment as well as the presence of the tritium and medical isotope targets) and must be considered when evaluating the radiological consequences of potential releases from the core. (The radiological consequences of the tritium production core inventory are not discussed within this report.)

\subsubsection{Reactivity Feedbacks}

The most significant effect of the new core design is a reduction in the Doppler coefficient by nearly an order of magnitude. On the other hand, the increased fuel enrichment 


\section{HNF-1732}

significantly increases the effect of axial movement of the fuel (i.e., increased reactivity feedback due to axial thermal expansion). Note that axial expansion of driver fuel adds negative reactivity. Whereas, axial expansion of the tritium targets adds a new, typically very small, but positive feedback mechanism. Axial contraction due to cooling reverses the sign of the above feedback mechanisms.

The SAS4A/SASSYS- 1 model of the new tritium and medical isotope production core incorporated all 81 of the fuel assemblies and all 106 of the tritium assemblies within various channels. The SAS4A/SASSYS-1 model used separate fuel and tritium target pin thermal models to calculate both the sign and magnitude of the axial expansion reactivity feedback during each of the design basis transients. The analyses, which are discussed in Section 6.1, indicate that the reactivity feedback effect due to the axial expansion or contraction of tritium target material is very small and is not very important. On the other hand, for the tritium and medical isotope production core, the reactivity feedback effect of fuel axial expansion or contraction is significant and typically exceeds the Doppler.

Not all of the reactivity feedbacks were included in the subject safety analyses. The subject safety analyses assumed reactivity feedbacks from Doppler, sodium density, and axial expansion of both the fuel and tritium targets. The amount of reactivity feedback due to Doppler and axial expansion or contraction of fuel or target material was varied depending on the type of analyses performed. (See Sections 6.3.1, 7.1, and 7.2 for additional discussion.) The FFTF FSAR assumed reactivity feedbacks from only Doppler and Sodium density. For both the FSAR and the analyses documented by this report, the analyses did not assume reactivity feedbacks from control rod driveline expansion or radial expansion and bowing.

\subsubsection{Other Neutronic Parameters}

Several other neutronic parameters associated with the new core design are calculated to change from the previous core design. In general, these changes are of less significance than the others discussed above, but the new values were included in the revised analyses. 


\section{HNF-1732}

\subsection{CODE DESCRIPTION AND VALIDATION}

It must be noted that the subject analyses have been performed with improved and updated computer codes. The existing FSAR design basis accident calculations were performed with codes developed specifically for the FFTF, such as MELT and IANUS (see Section 3.3). These codes are relatively simple compared to newer codes that were later developed to support the United States Liquid Metal Reactor program.

In particular, the SAS4A/SASSYS-1 code (DUNN 1985), developed by the Argonne National Laboratory, is used for all of the core accident analyses documented in this report. This code is a further development of the SAS3A code that was used for the existing FSAR unprotected loss-of-flow analysis. However, to maintain consistency with the cladding strain limits, the SASSYS-1 calculated power and flow transient results are used as input to the same cladding strain calculational model (i.e., MELTIII/FCF-213) used in the FSAR.

\subsection{SAS4A/SASSYS-1 VERSION 3.0 HANFORD REVISION 1.0}

The current release of the SAS code system is designated with the name SAS4A/SASSYS-1 Version 3.0. This computer code system was originally developed (DUNN 1985) at the Argonne National Laboratory for the thermal, hydraulic, and neutronic analysis of power and flow transients in liquid metal reactors (LMR).

The SAS4A portion contains detailed mechanistic models of transient thermal, hydraulic, neutronic and mechanical phenomena to describe the response of the reactor core components, coolant, and structural members to accident conditions. Originaliy developed to analyze oxide fuel clad with stainless steel, the models in SAS4A Version 3.0 have been extended to incorporate advanced fuels and cladding alloys. The core models in SAS4A provide the capability to analyze the initial phase of severe core disruptive events through coolant heat-up and boiling, fuel element failure, fuel melting and relocation.

The SASSYS-1 portion contains the same core models as SAS4A for fuel element heat transfer, including single and two-phase coolant thermal hydraulics. In addition, SASSYS-1 has the capability to model the thermal/hydraulic characteristics the primary and secondary sodium coolant loops, including heat transfer and removal equipment, such as intermediate heat exchangers (IHX), steam generators (SG), or air dump heat exchangers (DHX). SASSYS-1 also provides the capability to model the reactor control and protection system, as well as the control systems for the primary and secondary coolant pumps and the air dump heat exchangers, and their response to input signal changes. (The DHX control system and Plant Protection System are discussed in Sections 6.1.4.) 


\section{HNF-1732}

The SAS4A/SASSYS-1 Version 3.0 was converted to function on the engineering workstation environment at Hanford and modified to support the detailed design of the PPS and DHX control systems at FFTF and to output a highly specialized file containing all of the time dependent multi-channel temperature distributions. The modified Hanford version of the SAS4A/SASSYS-1 computer code is designated as Version 3.0 Revision 1.0.

\subsection{SAS4A/SASSYS-1 Code Installation Verification and Validation}

The SAS4A/SASSYS- 1 code as received from ANL was capable of running in double precision on a 32-bit SUN workstation. The SAS4A/SASSYS-1 code was converted to run in single precision on a 64-bit Silicon Graphics Indigo-2 R-10000 workstation containing 256 $\mathrm{Mb}$ of main system memory with IRIX 6.2 as the current level of the operating system. The Release 7.1 of the FORTRAN Compiler was used to compile and link each of the individual subroutines. The conversion was performed twice; once without the specific Hanford revisions necessary to support FFTF and once with. Most of the modifications necessary for conversion involve removing implicit double precision statements and modifying the vendor specific system utility call statements for time, date, process and user identification. The Hanford revisions required a moderate amount of revised coding in several control system subroutines and the additional of several new subroutines to support the steady-state and transient response of the DHX modules and to output the multi-channel temperature distributions.

The original ANL version of SAS4A/SASSYS-1, as converted without the Hanford revisions, was run using a sample input deck. Comparison of ANL and Hanford calculated results show exact agreement in virtually all printed values, except for a few very minor cosmetic difference due to compiler interpretation of some FORMAT statements, difference in system utility routines such as time, date, process, and user identification. In addition, some differences were noted in calculated results in the range of part-per-million. These differences will have no quantitative affects on the accuracy of the calculated variables. The excellent agreement between the Hanford and ANL computations verifies that the installation of the SAS4A/SASSYS-1 Version 3.0 was properly performed and are effectively identical.

The same sample problem was run for SAS4A/SASSYS-1 Version 3.0 with the Hanford revisions necessary to support the detailed design of the PPS and DHX control systems at FFTF, and to output a specialized file containing the time dependent multi-channel temperature distributions. Again, comparison of ANL and Hanford calculated results show exact agreement in virtually all printed results, except for a few very minor cosmetic difference due to compiler interpretation of some FORMAT statements, difference in system utility routines such as time, date, process, and user identification, and some input/output differences due to some new variables that were added to support the FFTF control system and dump heat exchanger. Several additional test cases modeling the DHX transient response 


\section{HNF-1732}

were run. The results of these test cases were compared against actual plant measurements. Again, excellent agreement was found. This verifies that the installation of SAS4A/SASSYS1 Version 3.0 Revision 1.0 was properly performed and the modifications installed by Hanford do not effect overall agreement.

\subsection{AUXILIARY SUPPORT PROGRAMS}

The SAS4A/SASSYS-1 computer code interfaces with six small auxiliary support programs (or computer codes). These codes, which usually contain less than a few hundred lines of FORTRAN coding, were written as either input pre- or output post-processors. The auxiliary support programs are: COMBINE, DECAY, DELAY, HOTSTUFF, PLOT11, and PLOT15.

Each of the auxiliary codes are discussed in the following sections.

\subsubsection{COMBINE Computer Code}

The COMBINE computer code was obtained from the Reactor Analysis Division staff at Argonne National Laboratory (ANL) and was successfully complied on the same Silicon Graphics Indigo-2 workstation as discussed above in Section 5.2. The COMBINE program is an input pre-processor. COMBINE reads assembly-dependent physics data, such as powers, flows, reactivity worths, etc., and processes (averages and normalizes) it into a form compatible with the user input requirements for a multi-channel (various assembly groupings) SAS4A/SASSYS-1 model. The Hanford version of COMBINE was modified to remove several plotting subroutine CALL statements, which are not available, and to allow the user input of a total Doppler temperature coefficient to be used for normalization purposes. Check cases were run using the same assembly-to-channel assignments as ANL and manually checking the output averaged values. (In SAS4A/SASSYS-1 terminology, the term "channel" is used to denote a basic elemental unit consisting of fuel, cladding, coolant, and structure. Therefore, a single SAS4A/SASSYS-1 channel may represent a single fuel pin, multiple pins in many assemblies, single assemblies, multiple assemblies, etc. In all cases, the elementary unit from a code structure and data management stand-point is an individual channel.)

\subsubsection{DECAY Computer Code}

The DECAY computer code as originally obtained from the Reactor Analysis Division staff at Argonne National Laboratory was designated as FITDKY (DUNN 1989). FITDKY was modified to function on a Silicon Graphics Indigo-2 workstation, as discussed above, and was renamed DECAY. DECAY was written to take a table of decay heat versus time after 


\section{HNF-1732}

shutdown and to produce input compatible with SASSYS requirements. DECAY calculates a series of fitting parameters referred to as "BETAs" and "LAMBDAs" via a six group least squares fitting technique. This treatment for decay heat using a number of decay heat product groups is very similar to the multigroup precursor treatment commonly used for delayed neutrons. (For additional detail see DUNN 1989.) Three sample cases, both input and output, were received with the code. These cases were run and compared against the sample output. Comparison of ANL and Hanford calculated results show exact agreement in virtually all printed results, except for a few very minor cosmetic difference due to compiler interpretation of some FORMAT statements, difference in system utility routines such as time, date, process, and user identification.

\subsubsection{DELAY Computer Code}

The DELAY computer code was written to obtain core average values of the delayed neutron fractions and decay constants by processing core physics data consisting of six group delayed neutron fractions and the corresponding decay constants for each of five fissile and/or fertile isotopes. The resulting whole core delayed neutron fractions and decay constants are used by the point reactor kinetics model in SASSYS to determine the transient reactor power.

\subsubsection{HOTSTUFF Computer Code}

The HOTSTUFF computer code is an interactive post-processor written to calculate hot channel temperatures. HOTSTUFF uses as input the multi-channel transient temperature distributions (fort.47) as output by SAS4A/SASSYS-1 Version 3.0 Hanford Revision 1.0, user input power peaking factors for the selected channels, and the FFTF FSAR hot channel factors (HCF). HOTSTUFF searches each requested channel for the maximum nominal cladding midwall temperature at each time step during a transient event and then calculates the corresponding hot channel temperatures. HOTSTUFF outputs the hot channel coolant, cladding outer diameter (OD), cladding midwall (MW), cladding inner diameter (ID), fuel outer diameter and the peak fuel temperatures for each time step for each requested channel at the axial elevation of the maximum clad midwall temperature. A series of manual check calculations were performed to verify correct code functionality. The maximum hot channel cladding midwall temperature can be compared with the FFTF FSAR temperature limits to assess fuel pin performance and cladding integrity. The FSAR cladding midwall temperature limits and integrity criteria were discussed in Section 3.2, summarized in Table 3-1, and shown in Figure 3-1. 
HNF-1732

\subsubsection{PLOT11 and PLOT15 Computer Codes}

Both PLOT11 and PLOT15 are output post-processors. PLOT11 and PLOT15 read the unformatted binary data files (fort.11 and fort.15) as output by SASSYS and process the requested information into a form acceptable for use by commercial plotting packages. These codes were originally received as a single program designated PLOTIT from the Reactor Analysis Division staff at Argonne National Laboratory, but were separated and extensively rewritten to support SAS4A/SASSYS-1 Version 3.0 Hanford Revision 1.0. 


\section{HNF-1732}

\subsection{MODEL DEVELOPMENT AND ASSUMPTIONS}

An improved and updated computer code is used to perform the analyses of the limiting protected design basis transient events for the tritium and medical isotope production core. In particular, the SAS4A/SASSYS-1 code (DUNN 1985), developed by the Argonne National Laboratory, is used for all of the core accident analyses documented in this report. This code is a further development of the SAS3A code that was used for the existing FSAR unprotected loss-of-flow analysis. However, to maintain consistency with the original basis for the cladding strain limits, the SASSYS-1 calculated power and flow transient results from the fast and slow transient overpower analyses are used as input to the same MELTIII/FCF213 cladding strain calculational model used in the FSAR.

\subsection{MODEL DEVELOPMENT}

The SAS4A/SASSYS-1 model for the transient analysis of the proposed tritium and medical isotope production core consists of two separate parts. These parts are; 1) a multichannel reactor core model, which can change from cycle-to-cycle, and 2) a balance-of-plant model, which usually remains constant from cycle-to-cycle.

A 22 channel core model, consisting of 12 driver fuel and 10 tritium target assembly channels was developed for the subject analyses. This relatively low number of channels is acceptable since fuel melting, cladding failure, and assembly-to-assembly failure propagation is not expected. The development of the 22 channel model used for the analysis of the limiting protected design basis events is discussed in Section 6.1.1.

The balance-of-plant model has been evolving over the past few years, as plant operational and test data became available. The balance-of-plant model allows for explicit hydraulic representation of various FFTF components such as the reactor core, vessel inlet and outlet plenums, various segments of the primary and secondary loops, including the loop isolation and check valves, the primary and secondary pumps, intermediate dump heat exchangers, and air dump heat exchangers. The transient performance of the balance-of-plant model provides the boundary conditions for the 22 channel core model during the protected design basis transient analyses. A 2 loop balance-of-plant model was used for the analysis of the design basis accidents and is discussed in Section 6.1.2.

\subsubsection{Channel Selection}

The proposed tritium and medical isotope production mission at FFTF utilizes 106 core locations for the placement of the tritium assemblies and 3 core locations for Medical 


\section{HNF-1732}

Isotope Assemblies (MIA). This includes 90 of the outer row locations, previously occupied by stainless steel reflectors, as well as 16 in-core locations for tritium assemblies.

A S4A/SASSYS-1 22 channel core model was developed given a core loading pattern representative of an end-of-equilibrium cycle (EEC). The initial steady-state assembly power distribution and power-to-flow ratios used for the analyses correspond to an end-ofequilibrium cycle (EEC) condition. These values were obtained from a series of fuel management studies performed in support of the tritium and medical isotope production core. The maximum core residence time for the driver fuel assemblies is expected to be 400 equivalent full power days (EFPD) or four 100-full power day cycles. The residence time of the tritium assemblies is expected to vary considerably, from 2 to as many as 12 cycles, depending on the radial location of the assembly. The residence time of the medical isotope production assemblies will depend on the final design and may involve a combination of incore assemblies and an excore rapid insertion and retrieval device for use with short lived isotopes.

The individual fuel assemblies were arranged into 12 SASSYS channels. The tritium assemblies were arranged into 10 SASSYS channels for a total of 22 channels. The driver fuel assembly channel selection criteria is based on similar assembly powers, similar assembly power-to-flow ratios, location within the same flow orifice zone, and similar residence times, with the exception of the peak power-to-flow ratio driver fuel assembly, which was assigned as a single assembly to a separate channel. This was acceptable since the analyses of the design basis events did not anticipate fuel melting, cladding failure, or assembly-to-assembly failure propagation.

The target assemblies, because of the low powers, were simply grouped into channels corresponding to the row and orifice zone where they are located, with the exception of the peak power-to-flow tritium assembly, which was assigned as a single assembly to a separate channel.

\subsubsection{Tritium Target Pin Thermal Model}

A tritium target pin model was developed that allowed the SAS4A/SASSYS-1 computer code to estimate the reactivity effect of target column expansion during the design basis transient events. The tritium target material is composed of Lithium Aluminate $\left(\mathrm{LiAlO}_{2}\right)$. Figure 6-1 presents a representative planar view of a tritium target pin. Note that the target pins contain a second inner clad of Zircaloy surrounding the target material, separated from both the target material and outer cladding by Helium filled gaps. There are 19 target pins per tritium assembly versus 217 fuel pins per driver fuel assembly. 


\section{HNF-1732}

A "multi-fuel" radial zone target pin model was constructed to explicitly treat the $\mathrm{LiAlO}_{2}$, Zircaloy inner clad, and Helium gaps. The target pins were designated as "fuel" pins, but with multiple fuel types. The corresponding thermo-physical properties for each fuel type were input as $\mathrm{LiAlO}_{2}$, Zircaloy, and Helium, as opposed to mixed enriched plutonium and uranium oxide (i.e., $\left.(\mathrm{Pu}, \mathrm{U}) \mathrm{O}_{2}\right)$. The target pin was not allowed to restructure and a center void was not allowed to form.

An equivalent thermal performance model for the target pins was derived by varying the conductance for the outermost gap until the channel averaged calculated axial expansion matched the value for the appropriate nominal steady-state power-to-flow conditions documented in Appendix A of this report. For transient conditions the reactivity feedback due to axial expansion or contraction was determined from the input reactivity worth values ( $\mathrm{dk} / \mathrm{k}$ per $\mathrm{Kg}$ ) for the tritium target pin clad and $\mathrm{LiAlO}_{2}$ absorber column.

The SAS4A/SASSYS-1 code contains two levels of detail for the calculation of the reactivity due to fuel axial expansion. The simple model, which was used for the tritium target pin model, differs from the second more detailed model mainly in the calculation of fuel motion (expansion or contraction) within the cladding jacket. In the simple model, the fuel and cladding motion are based solely on their thermal expansions. If the thermal conditions are such that the fuel is determined to expand freely, the total axial expansion is merely the sum of the axial expansion for each individual axial segment calculated using the average temperature of each segment and its difference from the nominal initial steady-state temperature.

The detailed axial fuel expansion model was used for the driver fuel pins. Fuel axial expansion is calculated using a generalized plane strain assumption. To find the axial plane strain, a total force balance is performed. If the fuel-cladding gap is open (free expansion), then the force summation contains no term for the effects of the cladding. If the fuel and cladding are in contact, then the cladding terms must be included in the force balance. Various options are available for selecting the combinations of axial plane strain, axial swelling, and crack volume. This selection is affected by the user definition of the input parameter NAXOP (Block 51, Location 20). Guidance was received from the Reactor Analysis Division with respect to the use of this key input parameter.

\subsubsection{Balance-of-Plant Model}

The subject design basis transient analyses used a two-loop balance-of- plant model developed from the original one-loop model. The balance-of-plant model provides the boundary conditions for the 22 channel core model during the design basis transient analyses. (The two-loop FFTF model was developed to allow the explicit analysis of single loop accidents, loop specific PPS instrumentation locations and measurements, and N-1 loop 


\section{HNF-1732}

operations.) Figures 6-2 and 6-3 present graphical line diagrams of the one- and two-loop plant models for FFTF. The balance-of-plant model allows for explicit hydraulic representation of various FFTF components; such as, the reactor core, vessel inlet and outlet plenums, various segments of the primary and secondary loops, including the loop isolation and check valves, the primary and secondary pumps, intermediate dump heat exchanger, and air dump heat exchanger. (The designations $\mathrm{CVx}, \mathrm{Sx}, \mathrm{Gx}, \mathrm{Ex}$, and $\mathrm{Tx}$, where $\mathrm{x}$ is a numeric value, correspond to the various compressible volumes, liquid segments, gas segments, liquid elements, and temperatures groups that were established during model development.)

The one-loop model, as shown in Figure 6-2, represents the three primary and three secondary loops at FFTF, as one primary and one secondary loop. Conservation of mass and energy is maintained through the use of a multiplicity factor. A multiplicity factor of three is applied where the "single" primary loop enters and exits the core vessel. This effectively triples the incoming flow from a "single" loop and allows the model to simulate the removal of three times the "single" loop flow from the vessel.

The two-loop model, as shown Figure 6-3, was constructed by simply duplicating the existing one loop input to obtain the second loop. The two-loop model incorporates additional detail and enhancements necessary to link the appropriate segments together and to represent the Dump Heat Exchanger (DHX) and support both the Reactor Control and Plant Protection System (PPS). The left hand side of the two-loop model represents one-loop and the right hand side represents the remaining two-loops. The multiplicity factors were changed appropriately.

\subsubsection{Reactor Control, Plant Control, and Plant Protection System Models}

The Reactor and Plant Control Systems provide control for routine normal operations, including removal of decay heat during reactor shutdown. These systems include a neutron flux control system, a control system for coolant flow, and a control system for the DHX sodium outlet temperature. The flow and DHX temperature control systems are duplicated for each of the three Heat Transport System (HTS) cooling loops.

The purpose of the Plant Protection System (PPS) is to automatically take the necessary actions to protect the public and plant when abnormal operating conditions occur. The PPS acts independently of the Reactor and Plant Control Systems.

6.1.4.1 Reactor and Plant Control Systems. The neutron flux control system operates the three primary control rods and the six secondary control rods. During normal operations the three primary control rods are fully withdrawn, while the secondary control rods are partially withdrawn and are used for power and long term reactivity control. The neutron flux control system is modeled in SAS4A/SASSYS-1 through the use of user specified power levels and 


\section{HNF-1732}

reactivity feedbacks and includes a conservative minimum specified scram worth versus time including time delays.

The sodium flow control system includes all equipment necessary to provide stable control of sodium flow in each of the three primary loops by varying the pump speed by use of liquid rheostats. The flow controller drives the liquid rheostat position control system. (The failure of the flow controller is assumed to be the initiating event for the CFR event.) The flow control system is modeled in SAS4A/SASSYS- 1 and includes user specified primary and secondary motor torque setpoints and various pump characteristics.

The 12 DHX modules at FFTF provide for energy removal from the reactor. The DHX control system consists of all necessary equipment to provide stable control of air flow through the DHX modules and maintain the DHX sodium outlet temperatures within prescribed limits. The DHX control system has been modeled in detail within SASSYS. Each of the DHX modules has a controller that uses measurements of the sodium outlet temperatures to adjust the fan speeds and position of the flow dampers (both coarse and fine dampers). The DHX control system also provides for reducing the air flow and closing the flow dampers in response to a reactor scram. This is necessary to prevent overcooling of the secondary sodium. The steady-state response of balance-of-plant model with the DHX modules was calibrated against test data from the initial design verification. The transient response of the balance-of-plant model with DHXs was calibrated and compared against measured FFTF acceptance test data for the scram to natural circulation from $100 \%$ power.

6.1.4.2 Plant Protection System. The Plant Protection System (PPS) consists of two independent separate Reactor Shutdown Systems (RSS) and a Containment Isolation System (CIS). (The CIS is not modeled by SAS4A/SASSYS-1 and is not discussed in this report.) Functionally, the PPS includes all instrumentation channels, power supplies, logic devices, and actuators associated with these systems.

The two independent Reactor Shutdown Systems consist of a primary and secondary shutdown system. The primary RSS causes the three primary rods to drop into the reactor. The secondary RSS cause the six secondary control rods to drop. By design, each of these systems is capable of terminating all Anticipated, Unlikely, and Extremely Unlikely events, even if the most reactive rod is not inserted.

The RSS shuts down (scrams) the reactor, along with removing power to the primary and secondary pumps and DHX fan motors, and issues control signals to reduce the DHX air flow, when any of the following off normal plant operating conditions occur:

- Nuclear power excursion

- Insufficient heat removal from the reactor 


\section{HNF-1732}

- $\quad$ Significant imbalance between the heat removal capabilities of the primary and secondary of any HTS loop

- Loss of offsite electrical power

- $\quad$ Manual scram.

The primary and secondary RSS trip functions are modeled in detail in SASSYS through the use of control system input (CSI) data blocks. Table 6-2 summarizes the trip inputs that are used for the primary and secondary shutdown systems. The two RSS systems are modeled separately within SASSYS and are actuated by different "calculated" plant variables. All RSS measurements, functional relationships, actuation limits and time constants are consistent with the requirements documented within the FFTF FSAR Chapter 17, Table 17.2.2-1 and Appendix F, with three exceptions. These exceptions are discussed in the following paragraph.

The nuclear power low and high startup flux functions in the primary RSS are not explicitly modeled in SASSYS, since these two functions are applicable only during reactor startup, which is not the limiting initial condition for the design basis events discussed in Section 3.2. (The nuclear power low and high startup flux functions can be simulated by changing the overpower setpoints consistent with the analysis.) Secondly, the loss of electrical power function within the secondary RSS is not modeled, since electrical power is not one of the calculated variables in SASSYS. However, the loss of electrical power can be simulated by the use of time delays controlling the scram reactivity as a function of time. Finally, one other function in the secondary RSS is partially modeled. This is the power permissive trip function, which involves three measured plant variables; the HTS bus voltage, which again is not a calculated variable in SASSYS, the reactor power, and primary loop flow. Only the relationship between the reactor power and primary loop flow is modeled for the power permissive trip function.

In addition to modeling the RSS functions, the CSI logic includes input controlling whether or not a scram occurs. Three user choices are available. They are:

- Any trip in the primary or secondary RSS causes a scram, including a user specified time of scram.

- At least one trip in both the primary and secondary RSS causes a scram

- $\quad$ No scram.

Finally, each individual trip function in either the primary and secondary RSS can be turned on or off depending on the type of analysis being performed. This is very crucial 


\section{HNF-1732}

when individual trip setpoints are being investigated and the reactor response must be determined.

\subsection{HOT CHANNEL FACTORS}

The use of hot channel factors (HCF) allows uncertainties in design, manufacturing, and operational variables to be conservatively accommodated during the initial design phase and safety analyses. Figure 6-4 presents the pin, assembly and core regions which were used to identify the various hot channel factors that would apply. Table 6-1 presents the direct, statistical, and combined three sigma FFTF FSAR hot channel factors that were used for the protected design basis transient analyses.

The HCFs have evolved over a long period of time and are generally determined on a three sigma basis and usually combined in a semistatisical manner. The hot channel factors presented in Table 6-1 are the same as Table F.4.1-4 in Appendix F of the FFTF FSAR. The same HCFs were applied to both driver fuel and tritium assemblies.

One method of applying hot channel factors uses the temperature differences across a key component, usually the maximum power fuel pin, within the core, as shown in Equation 6-1. (This is the method used by HOTSTUFF to determine the hot channel temperatures.) For example, the hot channel coolant temperature can be obtained by summing the first two terms of Equation 6-1. The hot channel cladding outer diameter temperature can be obtained by summing the first three terms and so forth. If necessary the hot channel fuel temperatures can be determined by applying the appropriate hot channel factors to the temperature differences across the gap and the fuel pellet and summing according to Equation 6-1.

$$
\mathrm{T}_{\mathrm{HC}}=\mathrm{T}_{\mathrm{INLET}}+\mathrm{F}_{\mathrm{COOL}}{ }^{*} \mathrm{dT}_{\mathrm{COOL}}+\mathrm{F}_{\mathrm{FLM}}{ }^{*} \mathrm{dT}_{\mathrm{FLLM}}+\mathrm{F}_{\mathrm{CLAD}} * \mathrm{dT}_{\mathrm{CLAD}} \quad \text { Equation 6-1 }
$$

Where,

$\mathrm{T}_{\mathrm{HC}}=$ Hot channel temperature,

$\mathrm{T}_{\text {INLET }}=$ Nominal channel inlet temperature $+15^{\circ} \mathrm{F}$,

$\mathrm{dT}_{\text {Cool }}=$ Axial coolant temperature increase,

$\mathrm{dT}_{\mathrm{FLM}}=$ Temperature difference across film,

$\mathrm{dT}_{\text {CLAD }}=$ Temperature difference across the cladding

$\mathrm{F}_{\mathrm{COOL}}=1.350$, combined hot channel factor for coolant

$\mathrm{F}_{\mathrm{FLM}}=2.750$, combined hot channel factor for film

$\mathrm{F}_{\mathrm{CLAD}}=1.185$, combined hot channel factor for cladding

Another method uses equivalent power multipliers and flow reductions to obtain the same if not more conservative cladding temperatures then through the explicit application of 


\section{HNF-1732}

the individual hot channel factors shown in Table 6-1. This method was used for the MELTIII/FCF-213 strain calculations that were performed for the transient overpower events (see Section 7.0).

The hot channel temperatures for the continuous flow reduction (CFR) events were determined using the explicit application (first method) of hot channel factors to nominal temperature distributions. The hot channel temperatures were determined via the HOTSTUFF post-processor using the time histories of the nominal temperature distributions as output by SASSYS in a specialized file.

\subsection{ASSUMPTIONS}

The following paragraphs describe the reactivity feedbacks, rationale for selecting the events to be analyzed, and the initial conditions that were assumed for the subject analyses.

\subsubsection{Reactivity Feedbacks}

The transient overpower event analyses, as documented within Chapter 15 and Appendix F of the FFTF FSAR, assumed the only reactivity feedbacks available were Doppler and Sodium density. The fuel axial expansion, structural (radial expansion and bowing), and control rod driveline expansion feedbacks were conservatively set to zero. (The fuel axial expansion, structural, driveline expansion feedbacks are actually negative and, thus, it is extremely conservative to ignore these beneficial effects on the course of the various transients.) As a further conservatism, the Doppler feedback was increased $20 \%$ for the heat removal reduction events and decreased $20 \%$ for the transient overpower events.

The continuous flow reduction (CFR) analyses, as documented in Chapter 15 and Appendix F of the FFTF FSAR, uses a different methodology for the application of reactivity feedbacks. Reactivity multipliers were used to force the core to the most conservative powerto-flow ratio. The resulting reactivities used for the CFR are considered somewhat unrealistic, but necessary to obtain the most limiting hot channel temperatures that could potentially occur.

For all the FFTF FSAR design basis events, either the primary or secondary RSS was assumed to actuate and terminate the event.

The transient overpower analyses as documented within this report assumed the following reactivity feedbacks: $80 \%$ of the nominal Doppler, $100 \%$ of the nominal sodium density, $100 \%$ of the calculated tritium assembly axial expansion, and $50 \%$ of the calculated driver fuel assembly axial expansion. The $50 \%$ driver fuel axial expansion assumption is 


\section{HNF-1732}

based on conservatively using a portion of the reactivity effect due to axial thermal expansion of the fuel during transient overpower events. Fuel axial expansion has always been present in FFTF, but was previously dominated by the large Doppler feedback. The fuel pin pellet and cladding designs for the proposed tritium production core are identical to the original Series I and II designs, with the exception of the cladding material.

For continuous flow reduction events, which cause the cladding to heat as the fuel and target material cools, the subject analyses used a similar technique as the FSAR. The amount of positive reactivity feedback due to fuel axial contraction was varied through the application a reactivity multiplier to obtain a core response that resulted in the most conservative powerto-flow ratio that could potentially occur.

The detailed axial fuel expansion model available in the SAS4A/SASSYS-1 computer code was used for the driver fuel pins. Fuel axial expansion is calculated using a generalized plane strain assumption. To find the axial plane strain, a total force balance is performed. If the fuel-cladding gap is open (free expansion), then the force summation contains no term for the effects of the cladding. If the fuel and cladding are in contact, then the cladding terms must be included in the force balance. Various options are available for selecting the combinations of axial plane strain, axial swelling, and crack volume. This selection is affected by the user definition of the input parameter NAXOP (Block 51, Location 20). The calculated reactivity due to fuel axial expansion, was reduced using the feedback coefficient multiplier EXPCOF (Block 13, Location 1263). For example, EXPCOF would be set to 0.50 to use only $50 \%$ of the calculated fuel axial expansion reactivity during a transient overpower event. Guidance was received from the Reactor Analysis Division with respect to the use of this key input parameter.

The simple axial expansion model was used to calculate the amount of reactivity due the axial expansion of the absorber columns. $100 \%$ of the calculated positive reactivity due axial expansion of the target assemblies was used during transient overpower events, when the absorber column is expanding. During the CFR events, when the absorber column is contracting inserting negative reactivity, none of the calculated reactivity was used.

This is accomplished through the input parameter EXPCFF (Block 63, Location 79). EXPCFF would be set to 1.00 during the transient overpower events and 0.000 during the CFR or LOF events. Guidance was received from the Reactor Analysis Division with respect to the use of this key input parameter.

Finally, consistent with the FFTF FSAR, no control rod driveline axial expansion or structural (radial expansion and bowing) reactivity feedbacks were assumed for the protected design basis transient events as analyzed by the 22 channel tritium and medical isotope production core SAS4A/SASSYS-1 model. The control rod driveline axial expansion and 


\section{HNF-1732}

structural feedbacks were conservatively set to zero through the use of the input parameters ICREXP and IRADEX (Block 1, Locations 31 and 36).

\subsubsection{Selection of Transient Events For Analysis}

A wide range of design basis reactivity insertion/transient overpower events and heat removal reduction loss-of-flow events were identified and analyzed in the FSAR. Only two reactivity insertion/transient overpower events were calculated to result in any significant fuel cladding strain and only one heat reduction removal/loss-of-flow event challenged the FSAR hot channel cladding midwall temperature. These limiting events have been reanalyzed as described in the following sections. It should be noted that the TOP reanalyses conservatively used the same initial power-to-flow ratio used in the FSAR rather than the reduced value for the new reference core. Whereas, the LOF analyses used the nominal values for the reference core and then applied hot channel factors to the results.

6.3.2.1 Reactivity Insertion (Transient Overpower) Events. The $3 \$ / s$ ( $4 \$$ total) reactivity insertion event is the design basis transient overpower event for the PPS; it bounds events such as meltdown of a single control or fuel assembly. This event is categorized as an Extremely Unlikely event. The FSAR calculation showed a calculated fuel cladding strain of $0.13 \%$, well below the limit for Unlikely events. Because of the reduced Doppler coefficient and changes in the delayed neutron parameters this transient event was selected to be reanalyzed for the new core. The results of this analysis are presented in Section 7.1.1

The FFTF FSAR calculations indicate that a very slow reactivity insertion event that results in a power increase of $0.032 \% / \mathrm{s}$, results in a higher calculated cladding strain than any reactivity insertion event $(0.28 \%$ cladding strain when terminated by the second RSS trip function). Although no credible mechanism could be identified for such an event, this event is just slow enough to avoid the positive rate of power increase RSS trip functions. This event is categorized as an Extremely Unlikely event. The results of the analysis are presented in Section 7.1.2

6.3.2.2 Design Basis Reduction of Heat Removal Event. Only one design basis reactor reduction of heat removal or undercooling event challenged and slightly exceeded the established cladding temperature limits in the FSAR (additional analyses were performed to demonstrate that the specified cladding strain limits were still met). This event was a continuous reduction in primary sodium flow caused by a failure in the flow control system. This event is commonly referred to as a Continuous Flow Reduction (CFR). All other events met the established temperature limits with considerable margin.

The CFR is considered an Anticipated event given termination with actuation of the RSS by the first trip encountered. The CFR is considered an Unlikely Event given the failure 


\section{HNF-1732}

of the RSS associated with the first trip followed by termination of the event with the actuation of the remaining RSS backup trip. Again, as with the reactivity insertion events, given the reduced Doppler coefficient and changes in the delayed neutron parameters the CFR event was reanalyzed for the new core. Two separate CFR analyses were performed for the tritium and medical isotope production core, given separate trips associated with the first and second backup RSS functions. The results of the CFR analyses are presented in Section 7.2.

\subsubsection{Initial Conditions}

All the transient analyses documented by this report were initiated from steady-state reactor conditions representative of $100 \%$ power and $100 \%$ flow, where $100 \%$ power corresponds to a total core power $400 \mathrm{MW}$ and $100 \%$ flow corresponds to a total mass flow rate of $1.748 \mathrm{E}+07 \mathrm{lbm} / \mathrm{hr}$. The individual assembly power and flow distributions were obtained for a representative end-of-equilibrium cycle (EEC) condition consistent with the definitions of $100 \%$ power and $100 \%$ flow.

The transient analyses simulated up to 60 seconds of steady-state operations prior to initiating the specific event to allow plant parameters such as reactor power, net reactivity, loop and channel flows, component temperatures, etc. to stabilize. The results presented in Sections 7.1 and 7.2, with the exception of Figure 7-1, do not include the pretransient period. 


\section{HNF-1732}

TABLE 6-1. HOT CHANNEL FACTORS AT $680^{\circ} \mathrm{F}$ INLET TEMPERATURE

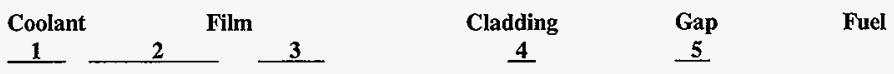

A. DIRECT

1. Inlet Flow Maldistribution

2. Intrasubassembly Flow

Maldistribution

3. Interchannel Coolant Mixing

4. Power Control Band

5. Wire Wrap Peaking

Direct Combination

$\begin{array}{llll} & 1.050 & 1.012 & \\ & & & \\ 1.140 & 1.035 & & \\ 1.00^{\mathrm{a}} & & & \\ 1.020 & 1.020 & 1.020 \\ & 2.000(1.214)^{\mathrm{b}} & \\ 1.221 & 2.137(1.297)^{\mathrm{b}} & 1.020\end{array}$

$\begin{array}{lllll} & 1.035 & 1.035 & & 1.035 \\ 1.079 & 1.079 & & 1.079 & \\ & 1.060 & 1.065 & & 1.065 \\ 1.011 & & & & \\ & & 1.266 & & \end{array}$

1.020

1.020

1.020

1.020

B. STATISTICAL

1. Fissile Fuel Maldistribution

2. Power Level Measurements

3. Nuclear Power distribution

4. Rod Diameter, Pitch, and Bow

5. Film Coefficient

6. Gap Coefficient

7. Fuel Conductivity

8. Cladding Conductivity

and Thickness

Statistical Combination

of Items 1-8

1.106

1.287

1.162

1.482

1.147

Products of Direct and

Statistical Combination ${ }^{b}$

1.512

1.170

(a) Worst Condition.

(b) Numbers in parentheses should be used only for calculating fuel temperatures, other for fuel cladding and coolant temperatures. 
HNF-1732

Table 6-2. Trip Inputs to the Reactor Shutdown System as for the Tritium Production Core.

\begin{tabular}{||l|l||}
\hline \multicolumn{1}{|c|}{ Primary Shutdown System } & \multicolumn{1}{c|}{ Secondary Shutdown System } \\
\hline \hline Primary Power Range Nuclear High Flux & Secondary Flux/Total Flow \\
\hline Primary Power Range Nuclear Low ${ }^{\left({ }^{a}\right)}$ & Secondary Flux-Increasing Delayed Flux \\
\hline High Startup Flux ${ }^{(a)}$ & Secondary Flux-Decreasing Delayed Flux \\
\hline Primary Flux-Decreasing Delayed Flux & Low Primary Loop Flow \\
\hline Primary Flux ${ }^{2}$ Loop Pressure & High Primary Loop Flow \\
\hline IHX Primary Outlet Temperature & Low Secondary Flow \\
\hline Reactor Vessel Coolant Level & Loss of Offsite Power ${ }^{(\mathbf{)})}$ \\
\hline Primary Flux-Increasing Delayed Flux & Reactor Outlet Plenum Temperature \\
\hline Pressure Permissive & Power Permissive \\
\hline Manual Scram & Manual Scram \\
\hline
\end{tabular}

(a) Not explicitly modeled, but can be simulated by changing overpower setpoints.

(b) Not explicitly modeled, but can be simulated by changing time delays.

(c) Partially modeled. 
HNF-1732

Figure 6-1. Representative Planar View of FFTF Target Pin.

Reference $\mathrm{LiAlO}_{2}$ FFTF Target Pin

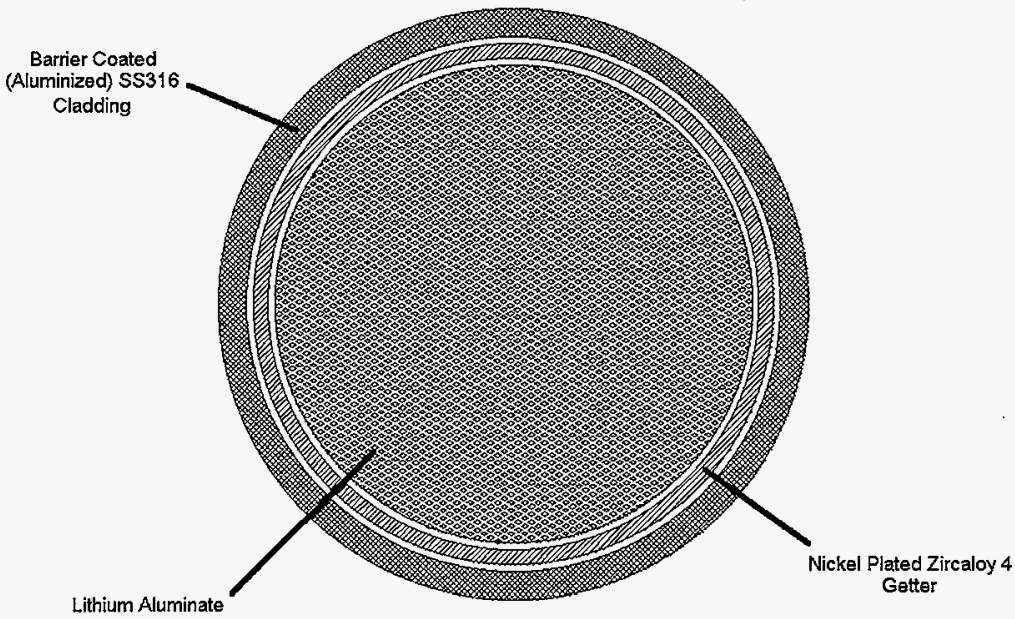

O.D. 0.938 inch

Not to Scale 


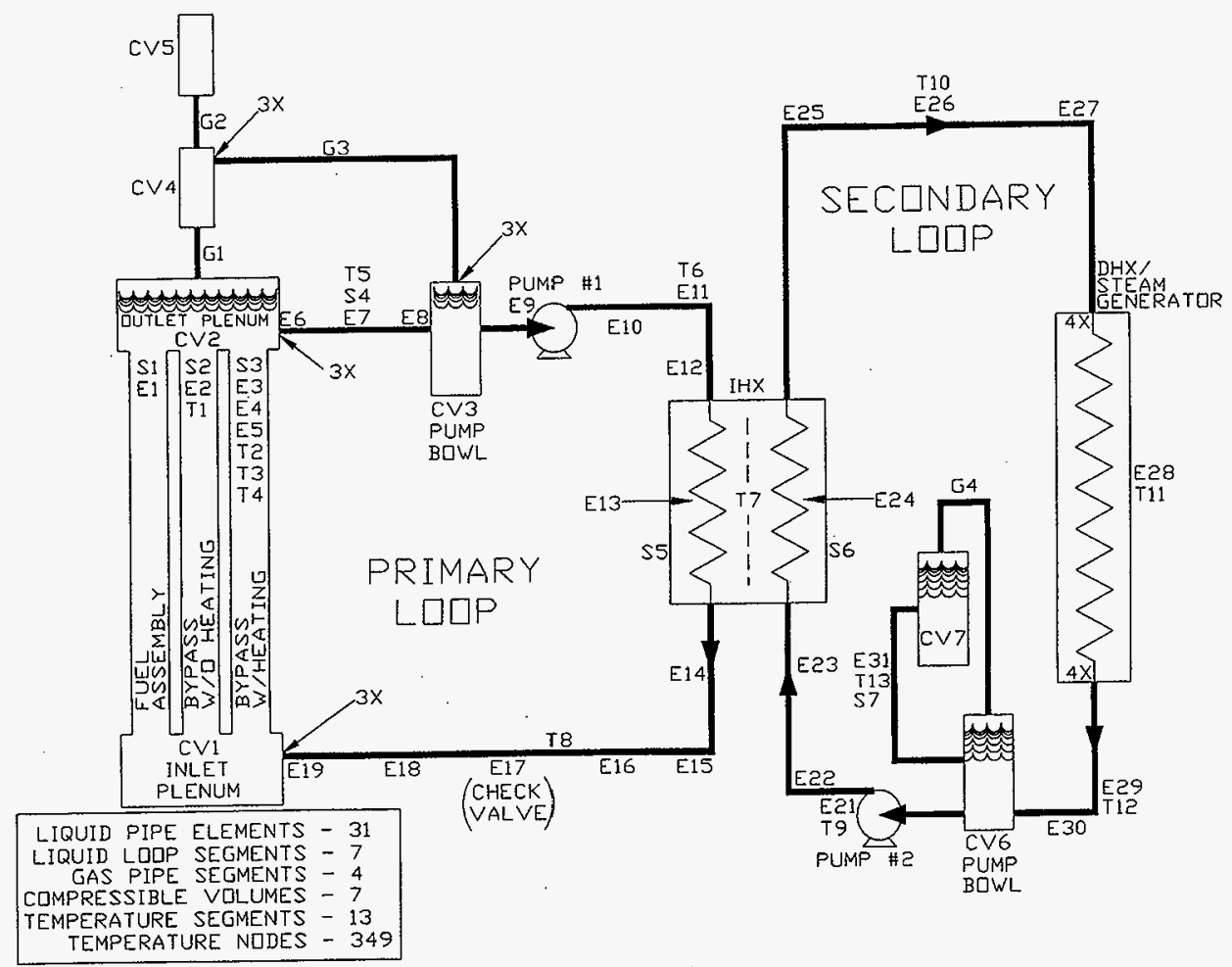



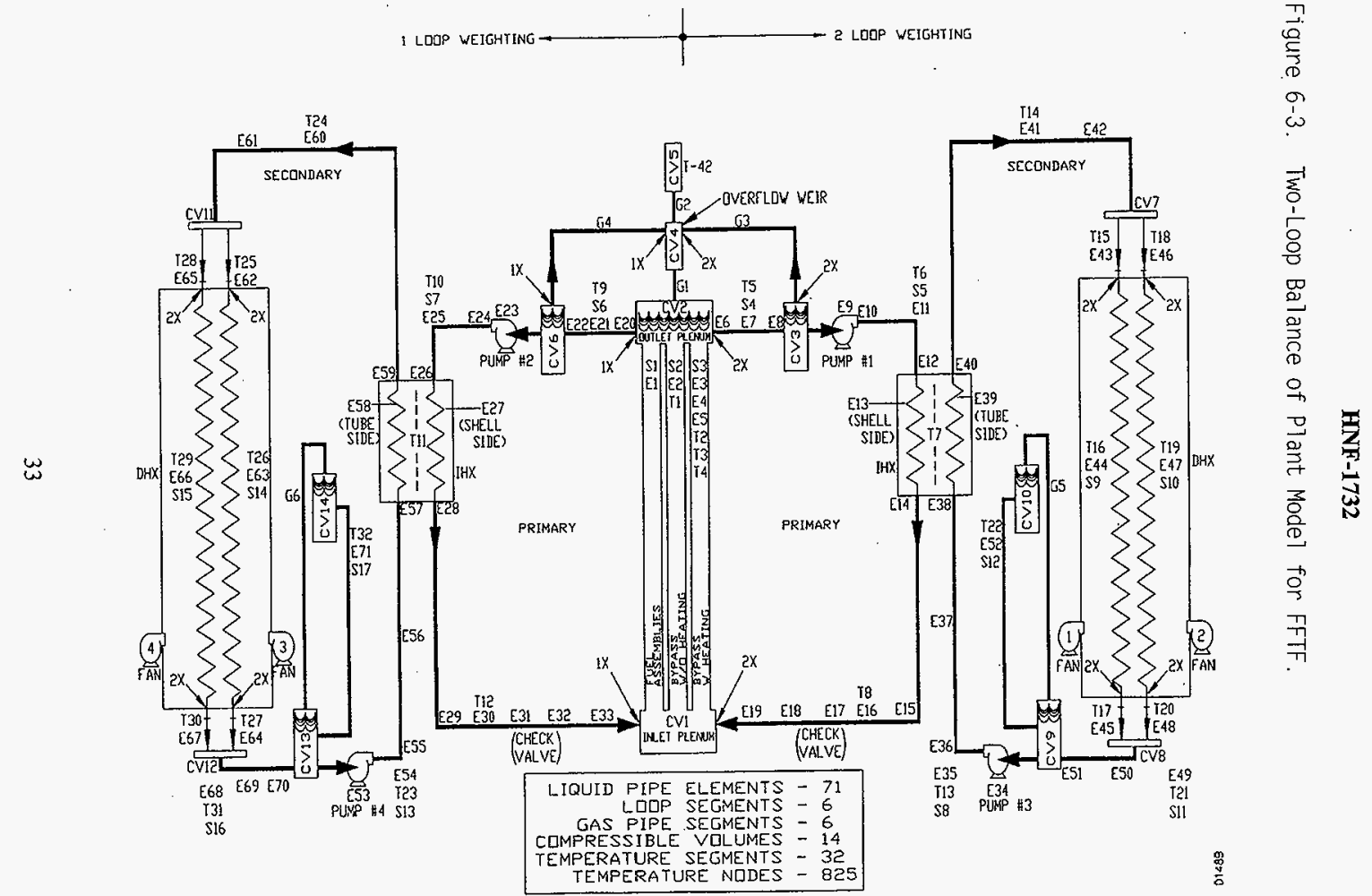
HNF-1732

Figure 6-4. Identification of FFTF Hot Channel Factors As Determined From Pin. Assembly, and Core Regions.

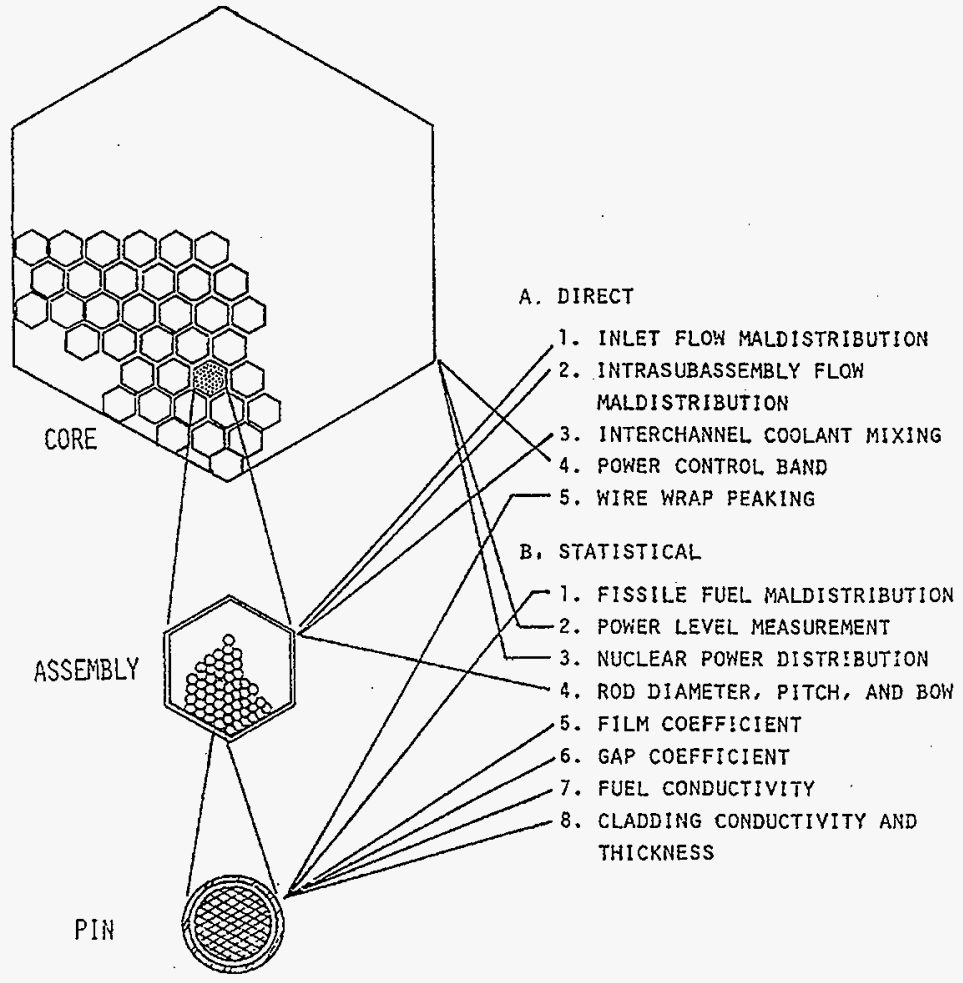




\section{HNF-1732}

\subsection{RESULTS OF THE PROTECTED DESIGN BASIS EVENTS}

Selected in-core events previously analyzed and documented within the FFTF FSAR have been reanalyzed for the proposed new tritium and medical isotope production core. The events selected for reanalysis are the most limiting protected design basis transient overpower and reduction of heat removal events as identified in the FSAR. The purpose of these analyses is to show that the existing Reactor Shutdown System (RSS) is adequate to maintain cladding strains and temperatures within the established limits for protected events to maintain cladding integrity. The results of the Transient Overpower analyses and cladding strain calculations are presented in Section 7.1. The results of the Heat Removal Reduction analyses are presented in Section 7.2.

\subsection{TRANSIENT OVERPOWER EVENTS}

The $3 \$ / \mathrm{s}$ and a $0.032 \%$ power $/ \mathrm{s}$ transient overpower events were used to evaluate the cladding strain. These transients produced nonzero cladding strain for the original FSAR. The relative severity of the transient strains are determined by the response of the plant protection system and the thermal response of the fuel. The results show that the cladding strains are below the FSAR limits and no fuel pin cladding failure is expected in either case. In addition, for both the transient overpower events that were analyzed the maximum hot channel cladding inner diameter temperature for the tritium target assemblies was determined to be less than $1500^{\circ} \mathrm{F}$.

\subsubsection{Fast Reactivity Insertion $(3 \$ / \mathrm{s})$}

The $3 \$ / s$ transient was analyzed using both the SAS4A/SASSYS-1 and the MELTIII/FCF-213 computer codes. The more sophisticated feedback models in SASSYS are better suited for modeling transients in the tritium production core. However, the FCF-213 cladding strain calculation is not available in SASSYS. The MELTIII computer code, not SASSYS, must be used to perform the transient strain calculations. The fuel axial expansion reactivity feedback is not modeled by MELTIII and must be incorporated indirectly through the transient power and flow histories obtained from SASSYS.

The resultant power and flow histories for the $3 \$ / \mathrm{s}$ transient overpower event, as obtained from SASSYS, were input to the MELTIII/FCF-213 computer code. Figure 7-1 presents the normalized reactor power and channel flow histories that were used for the strain analysis. The transient was initiated from a steady-state condition corresponding to $100 \%$ power and $100 \%$ flow. 


\section{HNF-1732}

The $3 \$ / \mathrm{s}$ transient as calculated by SASSYS produces a slightly lower peak reactor power than the FSAR reference case. The RSS is actuated by the primary high flux trip at $115 \%$ power. (If the transient had been allowed to continue, additional trips would have occurred at $116 \%, 118 \%$, and $126 \%$, due to exceeding the actuation limit of the Secondary Flux to Increasing Delayed Flux, Primary Flux to Increasing Delayed Flux, and the Secondary Flux to Flow trips, respectively.) Time delays associated with opening the control rod circuit breakers and decay of the magnetic field holding the control rods, allows the reactor power to overshoot before the assumed scram worth terminates the event.

MELTIII/FCF-213 was used to calculate the fuel, cladding and coolant temperatures and the cladding strain for the hot channel pin. The results are summarized in Table 7-1. The peak temperatures and powers for the tritium and medical isotope production core are lower than the FSAR reference case. However, since the initial peak pin power is lower, the fuel temperature is lower. The resulting calculated peak incremental transient cladding strain is $0.06 \%$, well below the limit of $0.4 \%$ for Unlikely events, thus no fuel pin cladding failure is expected.

The Doppler feedback is about an order of magnitude lower for the tritium and medical isotope production core when compared to the reference FSAR core. However, the total feedback for the tritium and medical isotope production core is more negative due to the inclusion of the fuel axial expansion, which MELT does not model. Inclusion of $50 \%$ of the calculated reactivity due fuel axial expansion results in a higher net negative feedback for the tritium and medical isotope production core, even with the reduced Doppler. Since feedbacks affect the transient power shape, the results are reduced peak power and peak temperatures for the tritium production core.

\subsubsection{Slow Reactivity Insertion (0.032 \%Power/s)}

The $0.032 \%$ Power/s transient assumes a non-mechanistic power transient just slow enough that the flux-to-increasing-delayed flux trips are not actuated. For this case, the MELTIII/FCF-213 computer code does not require power and flow histories from SASSYS. The transient is terminated by the backup secondary flux-to-flow trip at $126.5 \%$ power. This case was initiated from the same initial conditions as the $3 \$ / \mathrm{s}$ transient. The results are summarized in Table 7-2.

The peak coolant and cladding temperatures are about the same for the tritium and medical isotope production and FSAR reference cores. The fuel temperatures are lower for the tritium production core, which is expected since the peak assembly power is lower. However the cladding strain is slightly higher for the tritium production core due to the lower fuel melting temperature as a result of the higher enriched fuel. The lower fuel melting temperature results in a higher melting fraction during the transient. The FCF-213 


\section{HNF-1732}

model assumes a volume increase due to melting which reduces the fuel pin void volume and increases the cladding strain. The incremental cladding strain for the tritium production is significantly less than the total cladding strain limit of $0.7 \%$. No fuel pin cladding failure is expected.

\subsection{HEAT REMOVAL REDUCTION EVENTS}

The results of the heat removal reduction events, specifically two Continuous Flow Reduction transients, are presented in the following sections. The continuous flow reduction event, with trips on the first and second RSS functions, was reanalyzed for the new core. The CFR event is considered an Anticipated event given actuation of the RSS by the first trip and an Unlikely event given the failure of the first trip with actuation of the RSS by the second backup trip.

The intuitive notion that minimizing negative reactivity feedback is the most conservative does not apply here. For each of the two CFR transients that were analyzed, the search for the worst case temperatures uses a method in which the reactivity due to fuel axial expansion is varied via the input parameter EXPCOF. This is done to obtain the maximum power-to-flow ratio possible just prior to actuation of the RSS. (This is consistent with the FSAR, which used a reactivity multiplier designated as Mx.) Individual feedbacks are not as important as the net reactivity is in determining the maximum power-to-flow ratios during the CFR events.

As discussed in Section 6.3.2, the basis for this event was a failure in the flow controller that slowly reduces the speed of the primary pumps. The reactor power slowly decreases due to the effects of negative reactivity feedback as the sodium coolant temperature increases. If the flow decreases at a rate greater than the reactor power, the power-to-flow ratio will be greater than 1.0. As a result, the peak cladding temperature will increase. The worst case power-to-flow ratio is achieved at the intersection of two or more PPS trip functions. For the first trip the worst case occurs at the intersection of the secondary low primary flow and flux-to-flow PPS functions. For the second trip the worst case occurs at the intersection of the primary low pressure (i.e., pressure permissive) and flux squared-topressure PPS functions. For the anticipated design basis events the FSAR hot channel cladding midwall temperature limit is $1490^{\circ} \mathrm{F}$ for a peak assembly burnup of 80,000 MWd/MTM. For unlikely events the FSAR limit is $1584^{\circ} \mathrm{F}$ at $80,000 \mathrm{MWd} / \mathrm{MTM}$.

The results as discussed below show that the cladding temperatures are below the FSAR limits and no fuel pin cladding failure is expected in either case. In addition, for both the continuous flow reduction events that were analyzed the maximum hot channel cladding inner diameter temperature for the tritium target assemblies was determined to be less than $1500^{\circ} \mathrm{F}$. 


\section{HNF-1732}

\subsubsection{Continuous Flow Reduction Event - First Trip}

The 22 channel SAS4A/SASSYS- 1 model of the tritium and medical isotope production core was used to perform the transient analysis of the anticipated CFR event. The reactivity feedbacks used for the CFR analyses are as follows; 1) the nominal Doppler feedback was increased $20 \%, 2) 100 \%$ of the nominal sodium density, 3) no tritium assembly axial feedback, 4) no control rod driveline expansion, and 5) no radial expansion and bowing. The multiplier for the detailed fuel axial expansion model was varied searching for the worst case intersection with the secondary low primary flow and secondary flux-to-flow trip functions. The transient was initiated from $100 \%$ power and $100 \%$ flow steady-state conditions.

Figure 7-2 presents the transient power-to-flow ratio versus power for a CFR terminated by the first trip. The power-to-flow ratios versus power corresponding to the variable low primary flow and flux-to-flow actuation setpoints are also shown. The results indicate that the worst case power-to-flow ratio of 1.365 was obtained for a fuel axial expansion feedback coefficient multiplier (EXPCOF) of 0.5150. Table 7-3 summarizes the peak hot channel coolant and cladding midwall temperatures. Figure 7-4 presents the transient peak hot channel cladding midwall temperatures for both of the continuous flow reduction events.

The peak hot channel cladding midwall temperature was determined to be $1500^{\circ} \mathrm{F}$. This includes a $35^{\circ} \mathrm{F}$ increase to account for a $15^{\circ} \mathrm{F}$ uncertainty in the core inlet temperature and a $20^{\circ} \mathrm{F}$ increase to account for a combination of slightly more aggressive assembly powers and intra-assembly radial peaking factors corresponding to beginning-of-equilibrium cycle (BEC) conditions. (The calculated FSAR hot channel cladding midwall temperature for this event was $1516^{\circ} \mathrm{F}$.)

The maximum hot channel cladding midwall temperature for the continuous flow reduction given the first trip slightly exceeds the most conservative limit of $1490^{\circ} \mathrm{F}$. However, given the calculated assembly peak burnup of $67,000 \mathrm{MWd} / \mathrm{MTM}$, the actual FSAR limit is $1518^{\circ} \mathrm{F}$ (see Fiture 3-1).

The results show that the hot channel cladding midwall temperatures for the tritium and medical isotope production core are below the FSAR limits. No fuel pin cladding failure is expected during an anticipated CFR event. In addition, the maximum hot channel cladding inner diameter temperature for the tritium target assemblies was determined to be less than $1500^{\circ} \mathrm{F}$. 


\section{HNF-1732}

\subsubsection{Continuous Flow Reduction Event - Second Trip}

As with Section 7.2.1, the 22 channel SAS4A/SASSYS-1 model of the tritium and medical isotope production core was used to perform the transient analysis of an unlikely CFR event. The reactivity feedbacks used for these analyses are the same as those used for the analysis of the anticipated CFR event. The multiplier for the detailed fuel axial expansion model was varied searching for the worst case intersection with the primary low pressure (i.e., pressure permissive) and primary flux squared-to-pressure trip functions. The transient was initiated from $100 \%$ power and $100 \%$ flow steady-state conditions.

Figure 7-3 presents the transient power-to-flow ratio versus power for a CFR terminated by the second trip. The power-to-flow ratios versus power limits corresponding to the primary low pressure and primary flux squared-to-pressure actuation setpoints are also shown. The results indicate that the worst case power-to-flow ratio of 1.475 was obtained for a fuel axial expansion feedback coefficient multiplier (EXPCOF) of 0.2075 . Table 7-3 summarizes the peak hot channel coolant and cladding temperatures. Figure $7-4$ presents the transient peak hot channel cladding midwall temperatures.

The peak hot channel cladding midwall temperature was determined to be $1556^{\circ} \mathrm{F}$. This includes a $35^{\circ} \mathrm{F}$ increase to account for a $15^{\circ} \mathrm{F}$ uncertainty in the core inlet temperature and a $20^{\circ} \mathrm{F}$ increase to account for a combination of slightly more aggressive assembly powers and intra-assembly radial peaking factors corresponding to beginning-of-equilibrium cycle (BEC) conditions.

The maximum hot channel cladding midwall temperature for the unlikely continuous flow reduction event as terminated by the second backup trip is less than the most conservative limit of $1584^{\circ} \mathrm{F}$. See Figure 3-1. (The corresponding calculated FSAR temperature of $1588^{\circ} \mathrm{F}$ was determined to exceed the FSAR limits for a less than 10 seconds. Additional analyses were performed to demonstrate that the specified cladding strain limits were met.)

These results show that the hot channel cladding midwall temperatures for the tritium production core are below the FSAR limits. No fuel pin cladding failure is expected during an unlikely CFR event. In addition, the maximum hot channel cladding inner diameter temperature for the tritium target assemblies was determined to be less than $1500^{\circ} \mathrm{F}$. 


\section{HNF-1732}

Table 7-1. Results of the $3 \$ / \mathrm{s}$ Transient Overpower Analysis.

\begin{tabular}{||l|c|c||}
\hline \hline Parameter & FFTF FSAR case & $\begin{array}{c}\text { Tritium Mission } \\
\text { Case }\end{array}$ \\
\hline Peak Power/Initial Power & 3.91 & 3.56 \\
\hline Peak Fuel Temperature (K) & 2860 & 2794 \\
\hline Peak Cladding Temperature (K) & 1055 & 1033 \\
\hline Peak Coolant Temperature (K) & 1022 & 1000 \\
\hline Peak Cladding Strain (\%) & 0.13 & 0.062 \\
\hline Initial Fuel Temperature (K) & 2547 & 2507 \\
\hline Initial Cladding Temperature (K) & 967 & 967 \\
\hline Initial Coolant Temperature (K) & 934 & 935 \\
\hline
\end{tabular}

Table 7-2. Results of the $0.032 \%$ Power/s Transient Overpower Analysis.

\begin{tabular}{||l|c|c||}
\hline \hline Parameter & FFTF FSAR case & $\begin{array}{c}\text { Tritium Mission } \\
\text { Case }\end{array}$ \\
\hline Peak Power/Initial Power & 1.265 & 1.265 \\
\hline Peak Fuel Temperature (K) & 2995 & 2955 \\
\hline Peak Cladding Temperature (K) & 1047 & 1047 \\
\hline Peak Coolant Temperature (K) & 1007 & 1009 \\
\hline Peak Cladding Strain (\%) & 0.28 & 0.31 \\
\hline
\end{tabular}


HNF-1732

Table 7-3. Hot Channel Temperatures Obtained for the Continuous Flow Reduction Events.

\begin{tabular}{|l|c|c||}
\hline Transient (Peak Values) & $\begin{array}{c}\text { Temperatures }{ }^{\circ} \mathrm{F}\left({ }^{\circ} \mathrm{K}\right) \\
\text { Secondary RSS }\end{array}$ & $\begin{array}{c}\text { Temperatures } \\
\text { Primary RSS }\end{array}$ \\
\hline Time(s) of Peak Values & $31.3 \mathrm{sec}$ & $32.5 \mathrm{sec}$ \\
\hline Peak Power-To-Flow Ratio & 1.365 & 1.475 \\
\hline Coolant Outlet & $1442.0(1056.5)$ & $1495.0(1085.9)$ \\
\hline Clad Midwall & $1499.8(1088.6)$ & $1555.8(1119.7)$ \\
\hline
\end{tabular}


HNF-1732

Figure 7-1. Normalized Reactor Power and Channel Flow Versus Time for the $3 \$ / \mathrm{s}$ Transient Overpower Event.

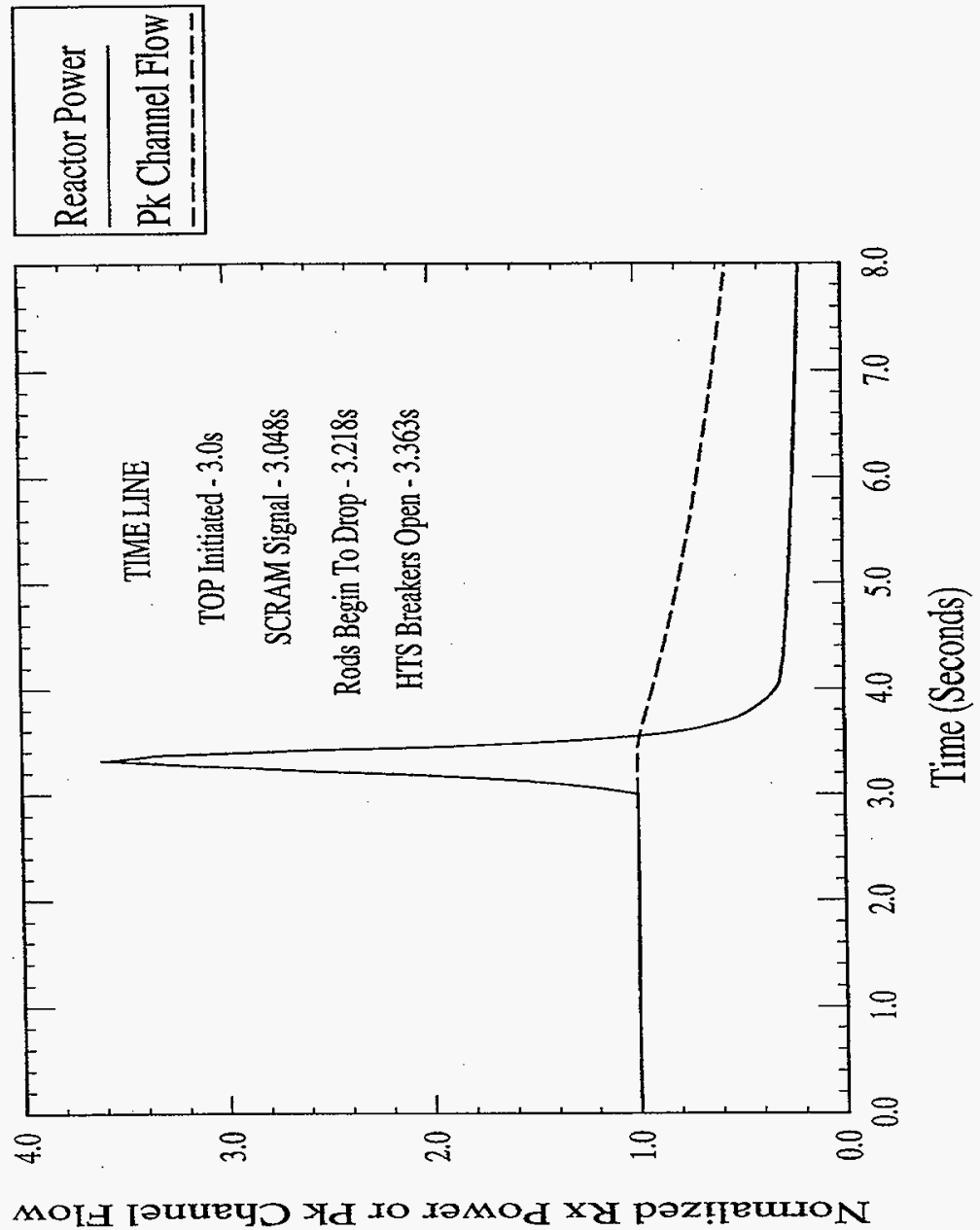




\section{HNF-1732}

Figure 7-2. Power-To-Flow Ratio Versus Power During a Continuous Flow Reduction Event for Secondary RSS Flux and Flow Related Trip Functions.
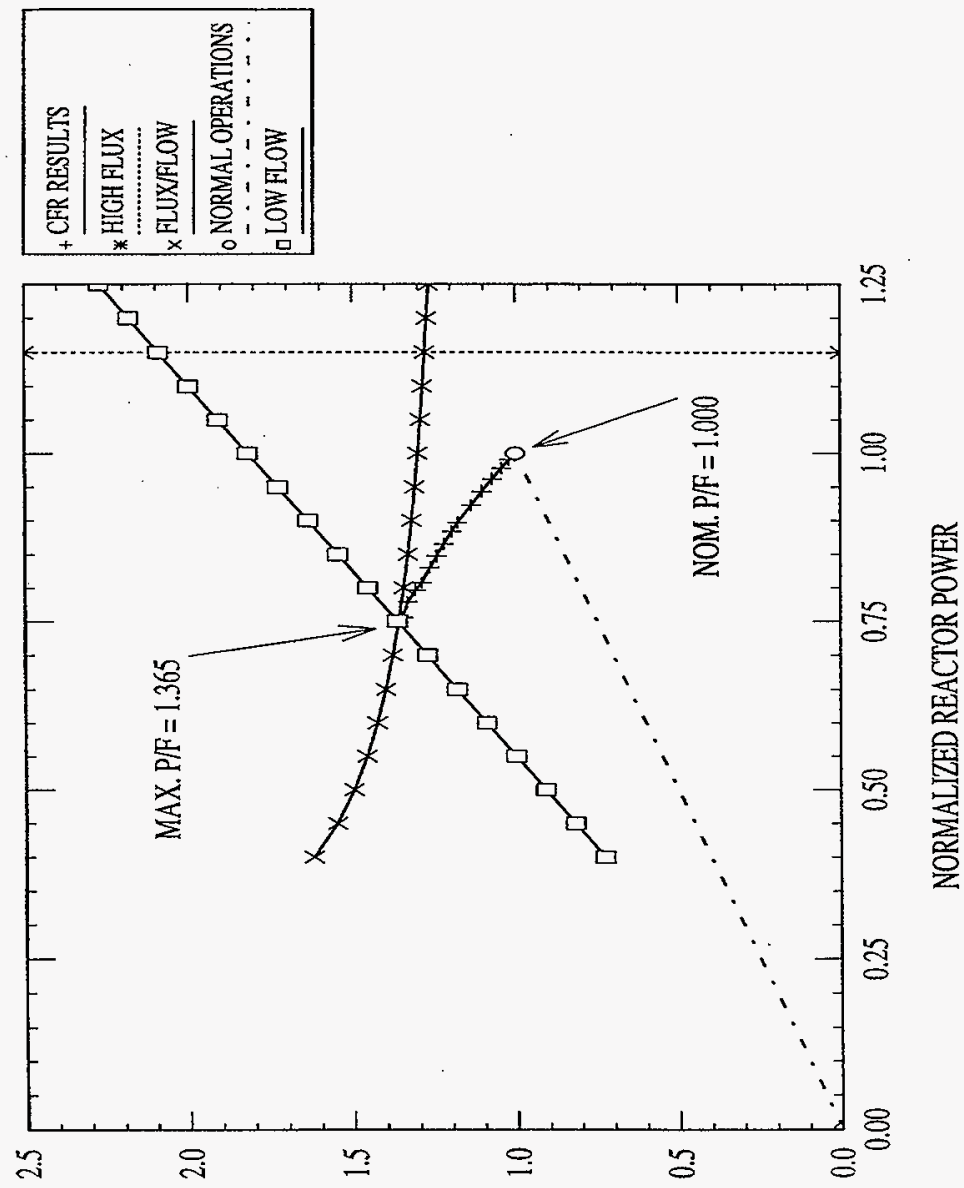

OILVY MOTH-OL-YGMOd YOLDVAZ वझZITVW 


\section{HNF-1732}

Figure 7-3. Power-To-Flow Ratio Versus Power During a Continuous Flow Reduction Event for Primary RSS Flux and Pressure Related Trip Functions.
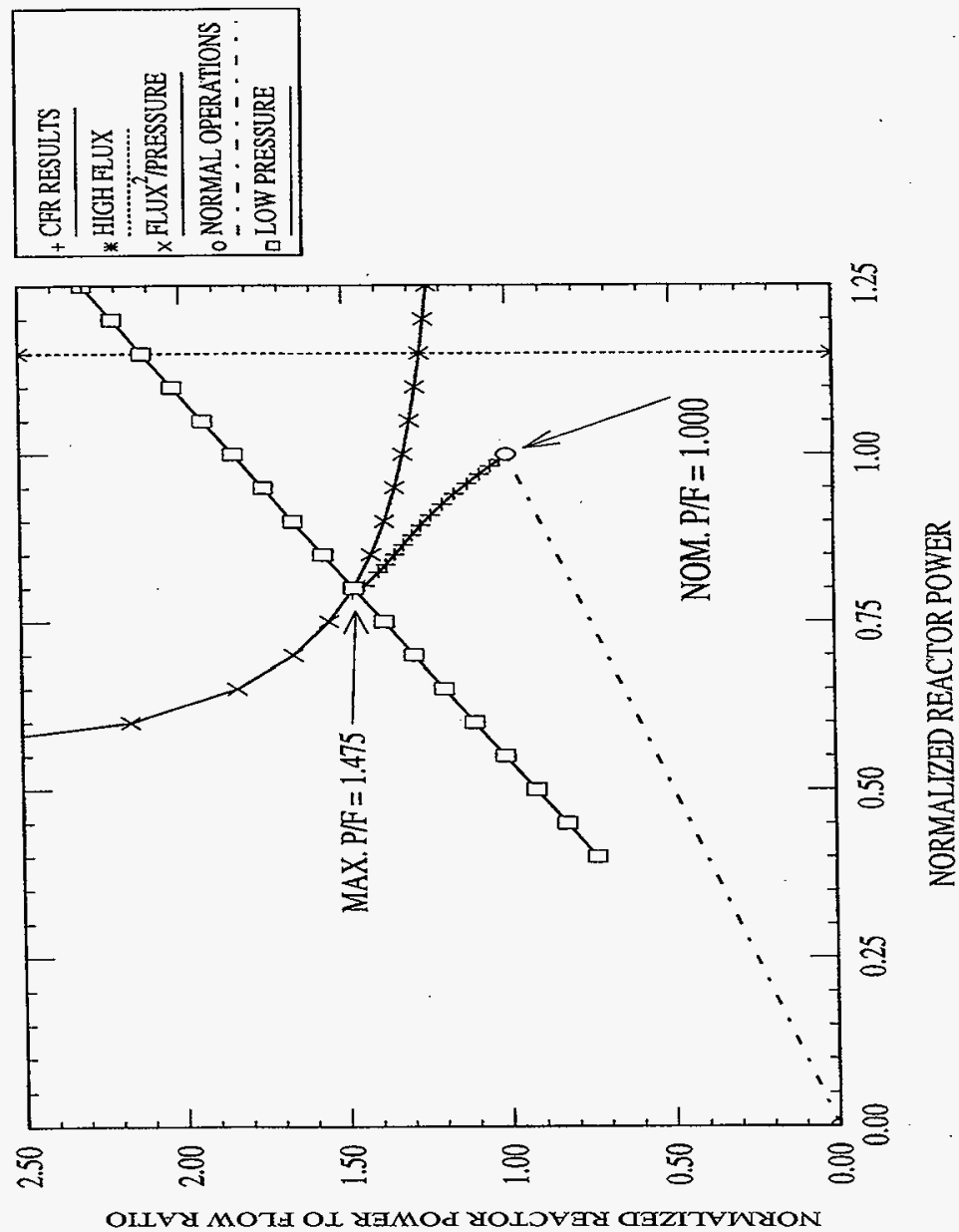
HNF-1732

Figure 7-4. Hot Channel Clad Midwall Temperature Versus Time During the Continuous Flow Reduction Events as Terminated By the Primary and Secondary RSS Trip Functions.

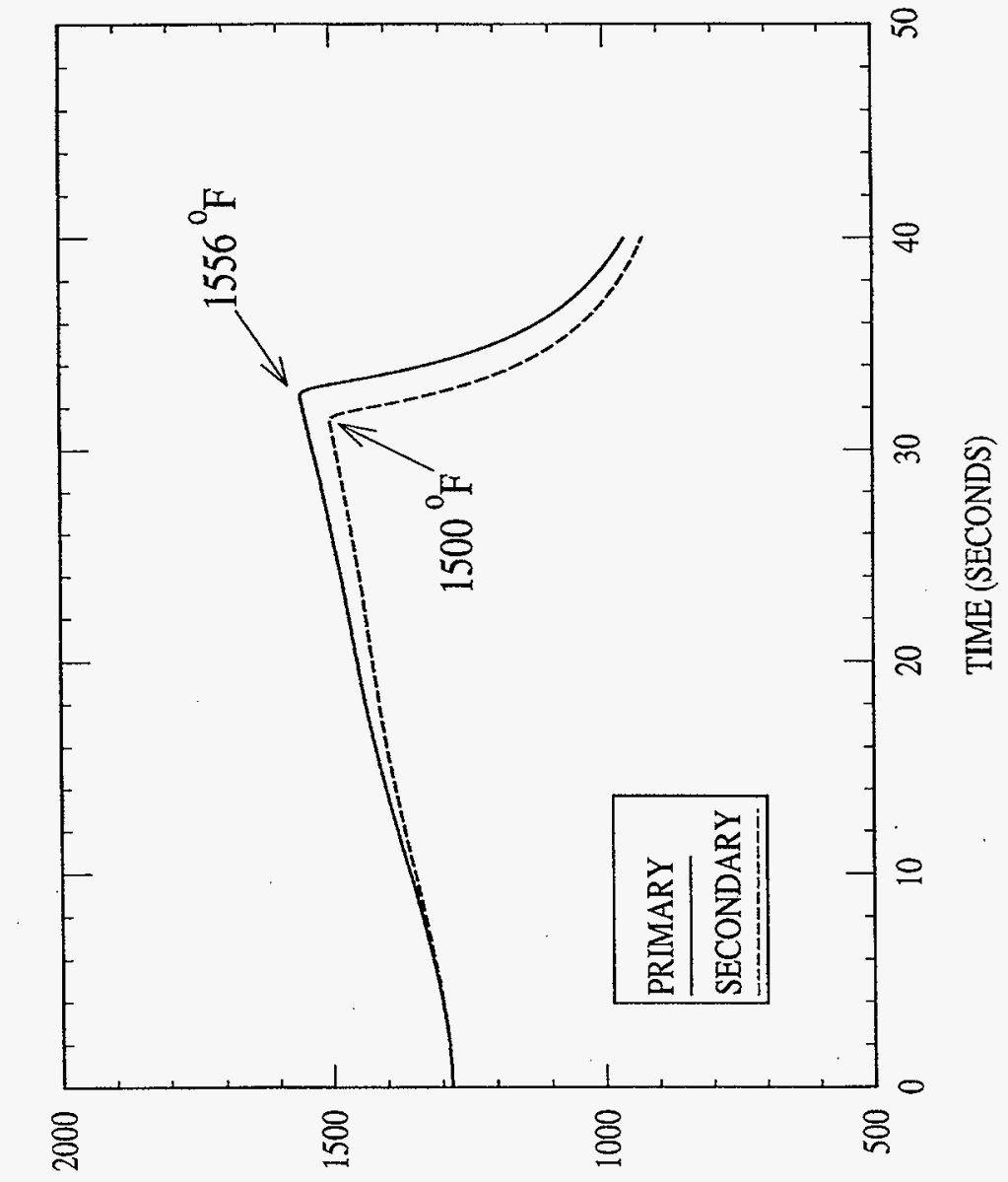

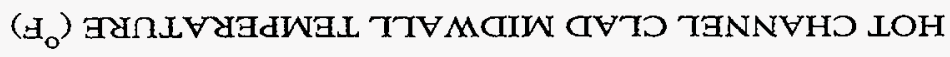




\section{HNF-1732}

\subsection{SUMMARY AND CONCLUSIONS}

Selected in-core accidents previously analyzed in the FSAR have been re-evaluated for the proposed tritium and medical isotope production core. The events selected for reevaluation are most limiting protected design basis events identified in the FSAR. The purpose of these analyses is to show that the existing Reactor Shutdown System (RSS) is . adequate to maintain cladding strains and temperatures within the established limits for the protected events.

The results of the analyses, as summarized in Table 8-1, show that, as expected, the protect transient results are quite similar to the existing FSAR results and that the RSS is indeed adequate to prevent fuel cladding failure for both the driver fuel and tritium assemblies.

For the extremely unlikely reactivity insertion events, a peak incremental cladding strain of $0.31 \%$ was calculated for the very slow reactivity insertion event versus a peak incremental cladding strain of $0.062 \%$ for very fast PPS design basis reactivity insertion event. In addition, for both reactivity insertion events the maximum hot channel cladding inner diameter temperature for the tritium target assemblies was less than $1500^{\circ} \mathrm{F}$. Note that maintenance of cladding integrity was not a criteria for the Extremely Unlikely events. For Extremely Unlikely events the assurance of Coolable geometry is required, by limiting the sodium coolant temperature less than $1670^{\circ} \mathrm{F}$. The existing FSAR analyses demonstrated that in fact the cladding strains and temperatures were expected to remain below the Unlikely event cladding integrity limits and, thus, no fuel pin failures are expected.

For the heat removal reduction events, a maximum hot channel cladding midwall temperature of $1500^{\circ} \mathrm{F}$ was calculated for the Anticipated CFR event, terminated by the first RSS trip. A maximum hot channel cladding midwall temperature of $1556^{\circ} \mathrm{F}$ was calculated for the Unlikely CFR event, terminated by the second backup RSS trip.

The maximum hot channel cladding midwall temperature of $1500^{\circ} \mathrm{F}$ for the Anticipated CFR event exceeds the minimum temperature limit of $1490^{\circ} \mathrm{F}$ for an assembly peak burnup of $80,000 \mathrm{MWd} / \mathrm{MTM}$. However, given the actual peak burnup of approximately $67,000 \mathrm{MWd} / \mathrm{MTM}$, the corresponding FSAR clad midwall temperature limit is $1518^{\circ} \mathrm{F}$. In addition, for both continuous flow reduction events the maximum hot channel cladding inner diameter temperature for the tritium target assemblies was less than $1500^{\circ} \mathrm{F}$. Therefore, fuel or tritium target pin failures are expected. 


\section{HNF-1732}

Table 8-1. Summary Comparison of the Calculated Design Basis

Transient Results for FSAR Reference and the Tritium Production Core.

$\begin{array}{lll}\text { Feak } & \text { Pear Result } \quad \text { New Core Result } \quad \text { Limit }\end{array}$

Slow Reactivity Insertion
$(0.032 \%$ Power/s)
$0.28 \%$ strain
$0.31 \%$ strain
$0.4 \%$ strain
Design Basis Transient
Overpower $(\$ 3 / \mathrm{s})$
$0.13 \%$ strain
$0.06 \%$ strain
$0.4 \%$ strain

Continuous Flow Reduction

(first RSS trip)

$1516^{\circ} \mathrm{F}$

$1500^{\circ} \mathrm{F}$

$1490^{\circ} \mathrm{F}^{(a)}$

Continuous Flow Reduction

(backup PPS trip)

$1588^{\circ} \mathrm{F}$

$1556^{\circ} \mathrm{F}^{\circ}$

$1584^{\circ} \mathrm{F}$

(a) Corresponds to a peak fuel burnup of $80,000 \mathrm{MWd} / \mathrm{MTM}$. Temperature limit is $1518^{\circ} \mathrm{F}$ for the calculated peak fuel burnup of $67,000 \mathrm{MWd} / \mathrm{MTM}$. 
HNF-1732

\subsection{REFERENCES}

Dunn F. E., et al., "The SASSYS-1 LMFBR Systems Analysis Code," Proc. Int. Topl. Mtg. Fast Reactor Safety, Knoxville, Tennessee, April 21-25, 1985, CONF-850410, Vol. 2, p. 999, U.S. Department of Energy (1985).

Dunn F. E., "Decay Heat Calculations for Transient Analyses," Transactions of the American Nuclear Society, Volume 60, pp. 633-634, 1989.

Fast Flux Test Facility Final Safety Analysis Report, HEDL-TI-75002, December, 1975. 
HNF-1732

APPENDIX A

Transient Performance of the FFTF Tritium Targets

A-1 


\section{Pacific Northwest National Laboratory}

Operated by Battelle for the U.S. Department of Energy

October 14, 1997

Dave Lucoff

B\&W Hanford Company

P.O. Box 1200

Richland, WA 99352

Dear Dave:

\section{RE: TRANSIENT PERFORMANCE OF FFTF TRITIUM TARGETS}

The following tables provide a description of the transient performance of the FFTF tritium targets. Table 1 provides the calculated results for FFTF target material column expansion as a function of target assembly flow rate and power. The numbers for column expansion are referenced from room temperature. No values are provided for those conditions where target material melting is predicted. Intermediate values in Table 1 may be obtained by interpolation. For evaluation of transients events, do not assume negative expansion during cool down since there is potential for pellet hangup and pellet column ratcheting.

Table 1. Target Expansion as Function of Target Flow and Target Power (Inches)

\begin{tabular}{|l|l|l|l|l|l|l|l|}
\hline Flow $(\mathrm{lbm} / \mathrm{hr})$ & $800 \mathrm{~kW}$ & $600 \mathrm{~kW}$ & $400 \mathrm{~kW}$ & $200 \mathrm{~kW}$ & $100 \mathrm{~kW}$ & $40 \mathrm{~kW}$ & $20 \mathrm{~kW}$ \\
\hline 31,600 & melting & 0.490 & 0.384 & 0.283 & 0.234 & 0.205 & 0.196 \\
\hline 15,000 & melting & 0.535 & 0.411 & 0.296 & 0.240 & 0.207 & \\
\hline 7,500 & melting & melting & 0.464 & 0.320 & 0.252 & & \\
\hline 5,000 & meiting & melting & 0.521 & 0.344 & 0.263 & 0.217 & 0.201 \\
\hline 3,000 & melting & melting & 0.641 & 0.396 & 0.287 & & \\
\hline 1,500 & melting & melting & melting & melting & 0.348 & 0.249 & \\
\hline 750 & melting & melting & melting & melting & 0.481 & 0.296 & 0.240 \\
\hline 300 & melting & melting & melting & melting & melting & 0.451 & 0.311 \\
\hline
\end{tabular}

Table 2 provides an estimate of the thermal time constant for the FFTF targets for various flow rates and assembly powers. The numbers in Table 2 are an estimate of the distributed parameter time constant based on the pellet temperatures at the rod mid-plane. The thermal 
Dave Lucoff

October 14, 1997

Page 2

time constants are close in value to lumped-parameter time constants defined as the heat content per unit rod length per degree divided by the heat loss per unit rod length per degree.

Larger thermal time constants are due to the opening up of the gaps between the internal components in the target. As before, no values are provided for those conditions where target material melting is predicted and intermediate values in Table 2 may be obtained by interpolation. The values provided in Table 2 are somewhat larger than the earlier lumped parameter values provided informally.

Table 2. Estimated Thermal Time Constant at Rod Midplane (Seconds)

\begin{tabular}{|l|l|l|l|l|l|l|l|}
\hline Flow $(\mathrm{lbm} / \mathrm{hr})$ & $800 \mathrm{~kW}$ & $600 \mathrm{~kW}$ & $400 \mathrm{~kW}$ & $200 \mathrm{~kW}$ & $100 \mathrm{~kW}$ & $40 \mathrm{~kW}$ & $20 \mathrm{~kW}$ \\
\hline 31,600 & melting & 40.6 & 34.0 & 30.1 & 28.1 & 27.3 & 26.8 \\
\hline 15,000 & melting & 42.7 & 34.9 & 30.3 & 28.4 & 27.3 & \\
\hline 7,500 & melting & melting & 37.1 & 31.2 & 29.0 & & \\
\hline 5,000 & melting & melting & 41.0 & 34.0 & 30.3 & 28.9 & 27.9 \\
\hline 3,000 & melting & melting & 56.0 & 42.8 & 37.1 & & \\
\hline 1,500 & melting & melting & melting & melting & 55.6 & 51.3 & \\
\hline 750 & melting & melting & melting & melting & 98.2 & 87.4 & 83.8 \\
\hline 300 & melting & melting & melting & melting & melting & 206.2 & 204.1 \\
\hline
\end{tabular}

If there are any questions, I can be reached at (509) $372-4135$.

Sincerely,

Bnushail

Bruce D. Reid

$\mathrm{BDR} / \mathrm{cs}$

cc: TM Burke, BWHC

KD Dobbin, FDNW

OA Farabee, DOE-RL

FJ Heard, NHC

DD Lanning, PNNL

EF Love, PNNL

File/LB

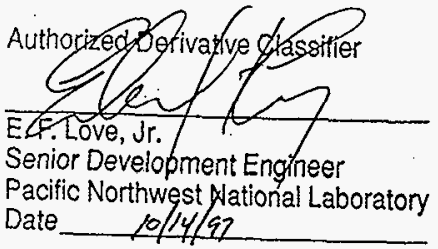

$A-3$ 


\section{DISTRIBUTION SHEET}

\begin{tabular}{|c|c|c|c|c|c|}
\hline \multirow{2}{*}{$\begin{array}{l}\text { To } \\
\text { Distribution }\end{array}$} & \multirow{2}{*}{\multicolumn{3}{|c|}{$\begin{array}{l}\text { From } \\
\text { NUMATEC Hanford Corporation } \\
\text { F. J. Heard }\end{array}$}} & \multicolumn{2}{|l|}{ Page 1 of 1} \\
\hline & & & & \multicolumn{2}{|c|}{$\begin{array}{l}\text { Date } \\
\text { November } 19,1997\end{array}$} \\
\hline \multicolumn{4}{|l|}{ Project Title/Work Order } & \multicolumn{2}{|c|}{ EDT No. 619617} \\
\hline \multicolumn{4}{|c|}{$\begin{array}{l}\text { Preliminary Scoping Safety Analyses of The Limiting Design Basis } \\
\text { Protected Accidents For The Fast Flux Test Facility Tritium } \\
\text { Production Core }\end{array}$} & \multicolumn{2}{|c|}{ ECN No. $N / A$} \\
\hline Name & MSIN & $\begin{array}{l}\text { Text } \\
\text { With All } \\
\text { Attach. }\end{array}$ & Text Only & $\begin{array}{l}\text { Attach./ } \\
\text { Appendix } \\
\text { Only }\end{array}$ & $\begin{array}{l}\text { EDT/ECN } \\
\text { Only }\end{array}$ \\
\hline
\end{tabular}

B\&W Hanford Company
J. D. Briggs
G3-42
$x$
T. M. Burke
N2-01
N2-53
N2-01
N2 -53
N2-11
N2-57
N2-57
$x$
S. Guttenberg
D. L. Nielsen
J. E. Parker
P. R. Prevo
R. O. Zimmerman

N2-57 $X$

NUMATEC Hanford Corporation
F. J. Heard
HO-34
$x$
E. R. Cramer
HO-34
$x$
Central Files
B1-07
Station 22 (EDT, SD Cover only)
N2-12

Date: 